\title{
An Optimality Analytical Approach to Selected Qur'anic Phonotactics
}

\author{
Presented by \\ Marwa Mohammed Ali \\ Assistant Lecturer \\ at
}

The Department of English Language and Literature

Faculty of Women for Arts, Science and Education

Under the supervision of

Associate Prof.

Heba Mohamed Ibrahim Aboul-Enein

Associate Professor of Linguistics

Department of English Language,

Faculty of Women, Arts, Science and

Education

Ain Shams University
Associate Prof.

Yahya Farghal Abdel-Mohsen Associate Professor of Linguistics

Department of Arabic Language, Faculty of Women, Arts, Science and

Education

Ain Shams University

\author{
Lecturer \\ Dina Mohammed Hamdy \\ Lecturer of Linguistics \\ Department of English Language, \\ Faculty of Women, Arts, Science \\ and Education \\ Ain Shams University
}

|لمستخلص

تهدف هذه الدراسة إلى تتبع الضو ابط الصوتية فى اللغة العربية من خلال بعض أحكام التجويد

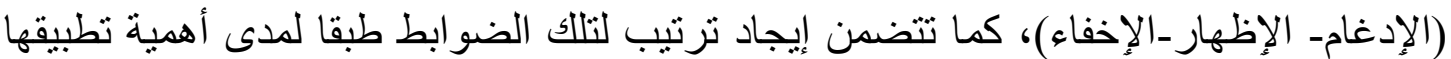

فى اللغة العربية فى إطار نظرية التفاضلية الصوتية. وتسعى الدراسة للإجابة عن الأسئلة الأنية :

$$
\begin{aligned}
& \text { ا ـ ما هى الضوابط الصوتية فى لغة القران الكريج؟ } \\
& \text { r - ما هو ترتيب هذه الضو ابط حسب أولويتها في لغة القران الكريج؟ }
\end{aligned}
$$


وقد اعتمد البحث على تفحص بعض أحكام التجويد و الضوابط الصوتية فى اللغة العربية بالإضافة إلى إستخدام نظرية التفاضلية الصوتية (Optimality Theory in Phonology) كآداه توظف من أجل تحليل وترتيب تسلسل تللك الضو ابط.

\section{An Optimality Analytical Approach to Selected Qur'anic}

\section{Phonotactics}

\section{Abstract}

After the Islamic conquests, everyday Arabic has changed considerably from Classical Arabic (CA) in which the Holy Qur'an was revealed. As a result of such variation, Arab Muslims are required to learn CA in order to recite the Qur'an in a correct way. Consequently, a set of phonological rules, i.e. tajweed rules, have been formed to facilitate reading the Qur'an. This study aims to present a constraint-based analysis of some the Qur'anic phonotactics, i.e. Al-'Idghaam, Al-'IZhaar, and Al-'Ikhfaa'. The framework which is followed in this paper is that of the Optimality 
Theory (OT) in phonology, a theory proposed by Prince and Smolensky (1993) in their book Optimality Theory: Constraint Interaction in Generative Grammar. The current study seeks to explore the CA constraints upon which the chosen tajweed rules are built. Furthermore, the study attempts to introduce a ranking of these constraints, i.e. 'a constraint dominance hierarchy', according to their importance in CA contexts. Some of the results that the study uncovers are that the different types of 'Idghaam and 'Ikhfaa' in the presented examples are built upon a ranking in which OCP principle; either OCP-total or OCP-feature (place or manner), occupies the highest rank, while Ident-IO (F) is in the lowest rank. Conversely, Ident-IO (F) comes at the highest rank in 'IZhaar in the chosen examples.

Keywords: Optimality theory in phonology, Qur'anic phonotactics, Classical Arabic constraints, constraint dominance hierarchy.

\section{Introduction}

\subsection{Arabic Language}

Classical Arabic is the Language of the Holy Qur'an (LHQ, following Al-Hashimi, 2004), which was revealed to the Holy Prophet Muhammed (pbuh) in the $7^{\text {th }}$ century CE. After Islamic conquests, Arabic has undergone several changes, due to its contact with different languages. As a result of these changes, Muslims, far and wide, need to learn CA in order to recite the Qur'an in a correct way. A study, conducted by the Washington-based Pew Research Center, has uncovered that $23 \%$ of the world population, about 1.6 billion, are Muslims, the majority of whom do not speak Arabic as their native tongue. Therefore, many Muslims essay to recite the Holy Qur'an in its original language instead of simply reading its translation in other languages (Study, 2012). 
Consequently, Tajweed rules have been formulated to facilitate reading the Qur'an, as it was revealed to the Holy Prophet Muhammed (pbuh).

\subsection{Tajweed Rules}

'Tajweed' literally means to improve or to accomplish something in a better way. It is a branch of science, which refers to the phonological rules governing pronunciation during the recitation of the Holy Qur'an. Thus, Tajweed is a significant part of the recitation of the Qur'an. Writing in the science of Tajweed started in the second century of Hijra, and it was not until the third century of Hijra that Al-'Imaam Abu Subayd AlQaasim Ibn Sallaam introduced the first book in this science of 'AlQiraa'aat. In the fourth century of Hijra, Tajweed was crystallized as a separate science by Abi Muzaafim Al-Khaqaaniy.The main purpose of the science of Tajweed is to make the reader proficient in reciting Qur'an, and to produce the correct pronunciation of every sound, according to the rules of recitation (Rashed, n.d., p.1). Tajweed rules are bound by certain constraints on pronunciation. A number of such rules and some of these constraints constitute the core of this study.

\subsection{Aim of the Study}

This paper aims to examine the three Qur'anic phonological processes of Al-'Idghaam, Al-'Ikhfaa', and Al-'IZhaar under the theoretical framework of Optimality Theory (OT) in phonology. It endeavors to provide a hierarchy of Classical Arabic constraints, upon which the chosen tajweed rules are built, under OT.

\subsection{Research Questions}

This study sets to answer basically two questions:

1. What are the Arabic constraints used for the three selected tajweed rules: Al-'Idghaam, Al-'Ikhfaa' and Al-'IZhaar?

2. What is the ranking of these constraints, according to their importance in the Language of Holy Qur'an (LHQ) in the chosen examples?

\subsection{Methodology}

\subsubsection{Corpus and Sources of Data}


The corpus, which provided the database for the study, was restricted to the three tajweed rules: Al-'Idghaam, Al-'Ikhfaa', and Al'IZhaar, as applied to Qur'anic verses. Tajweed rules, in this study, were mainly extracted from three ancient tajweed poems. The first one is $\mathrm{Al}$ Jazariyyah by Al-Jazariy, a distinguished and prolific scholar in the field of 'Al-Qiraa'aat, who lived in the middle of the $8^{\text {th }}$ century Ah. He was born in $751 \mathrm{Ah}$, wrote his poem Al-Jazariyyah in $798 \mathrm{Ah}$, and died in the $9^{\text {th }}$ century Ah, in $833 \mathrm{Ah}$. The second and the third poems are Tuffatu-l'ATfaal and kinzu Al-MaSaany bi-Tahriir Hirz Al-'Amaany by AlJamzuuriy. Al-Jamzuuriy was an Egyptian reciter who lived in the $12^{\text {th }}$ century Ah. He was born around $1160 \mathrm{Ah}$, but the year of his death is unknown. He wrote his poem Tuffatu-l-'ATfaal in 1198 Ah. However, nobody knows when he wrote kinzu Al-MaSaany.

In addition to these poems, the researcher utilized some tajweed rules from Sibawayh's original book Al-kitaab, written in the $2^{\text {nd }}$ century Ah. Moreover, the researcher checked translated works of Sibawayh for convenience. As for the explanation of the tajweed rules tackled in this study, it was taken from Taysiir Ar-Rahmaan fi Tajweed Al-Qur'an by SuYaad Abdel-Hameed; a T.V series "Al-'Itqaan li-tilaawat Al-Qur'an" by Ayman Swayd, and a website "MawsuuYat An-Nabulsi li-t-Tajweed". Furthermore, the Qura'nic examples of the analysis and their translations were quoted from two websites: "Al-Awfa" and "Al-Musfaf Al'Iliktruuniy" by King Saud University.

As for the Classical Arabic constraints, the researcher mainly exploited some OT universal constraints to be examined in LHQ. She selected these constraints from the following works: Al-Hashimi's (2004) M.A thesis The Phonology of nasal $n$ in the Language of the Holy Qur'an; Suzuki's (1998) $\mathrm{PhD}$ thesis A typological investigation of dissimilation, Van Goch's (2010) M.A thesis The obligatory contour principle: Consonant co-occurrence restrictions in Dutch, Goodman's article (n.d.) "Takelma Dissimilation and the Form of the OCP", Cohn's article (2014) "Phonology: Sound Structure", and McCarthy's article (1988) "Feature geometry and dependency". Finally, the researcher checked such CA constraints in Sibawayh's book, Al-kitaab; hence, reference would be made frequently to his original work for precision.

\subsubsection{Method, Sampling, and Procedures}


The theoretical framework followed in this paper is Prince and Smolensky's Optimality Theory in phonology. For convenience, and because of applying the same theory to LHQ, the researcher frequently consulted Al-Hashimi's (2004) thesis. Like her, the researcher chose similar constraints, applied violation table and stratified domination hierarchy.

In this study, a list of phonetic symbols was provided which the researcher used in the transcription of the selected words/phrases. Then, the researcher made a selection of three Tajweed rules and some words or phrases from the Holy Qur'an, in which these tajweed rules were applied. Such words or phrases were transcribed according to Hafs recitation. Afterwards, each rule was explained according to Arab phoneticians' expositions, with examples provided. Then, the selected words/phrases were subjected to a constraint-based analysis under OT in phonology. The researcher exhibited all the possible candidates according to what the Arab phoneticians postulated. In addition, she chose some of the Arabic constraints that accounted for the conditions upon which these rules were applied or banned. Furthermore, she examined the most prominent constraints in each example. Subsequently, she illustrated the different possible candidates for every word/phrase including the optimal/real pronounced one. Therafter, she presented the ranking of the selected constraints used in this study, upon which each rule is based. By the end of each section, the researcher referred to other identical examples utilizing the same ranking. Finally, the researcher displayed sets of constraint dominance hierarchies used for each rule at the end of every section.

\section{Part 1.}

\subsection{Theoretical Framework}

The theoretical framework, upon which this study is conducted, is OT in phonology. OT was proposed by Alan Prince and Paul Smolensky (1993) in their book Optimality Theory: Constraint Interaction in Generative Grammar. In addition, McCarthy $(2002,2007,2008, \&$ 2011) has made great contribution to OT. In his works, he describes the mechanism of OT and its basic components, gives a clear guide to how to apply OT, and highlights the common mistakes which are made by analysts during applying OT. McCarthy (2008) points out that although OT has been initiated in phonology and has a great effect on it; yet, it is also used in syntax, sociolinguistics, historical linguistics, and other branches in linguistics (p.1). 


\subsection{Review of Literature}

\subsubsection{Origin of OT}

In 1993, Prince and Smolensky launched a new theory of human language. They explained that this new theory was developed from generative grammar, and that it aims to show how the phonological systems are organized. They clarified in their article "Optimality Theory in Phonology" that "[g]enerative phonology ... aims to construct a predictive theory of natural language sound systems, rooted in a finelydetailed account of the principles defining linguistic representations and the possible relations between them" (2002, p.1). Hence, it focuses on the universal aspects of rules.

According to Chomsky, universal grammar is "the innate knowledge of language that is shared by normal humans - it characterizes both the universal properties of language and the variation tolerated among specific languages". Thus, linguists aim to study two central areas: the characteristics which are shared by all languages "language universals", and the variations found between languages "language variation". As a result, linguists set to determine the properties of a certain language and examine whether they are found in other languages (as cited in Archangeli, 1997, p.2). Within this broad concept, OT was generated: it was considered as a development of generative grammar sharing its focus on the investigation of universal principles. It examines two basic notions "Universality" and "Difference" between languages, i.e. languages may share some patterns, and at the same time, they may have their own patterns (Prince \& Smolensky, 2002, p.1). Nevertheless, OT differs from other phonological theories in some respects, which are identified briefly in this paper.

The traditional phonological theory of Chomsky and Halle (1968), The Sound Pattern of English (SPE), is based on rewriting rules. It is defined as "a general model of how grammars are structured"; which depends on using rules. In spite of the fact that these rules can describe numerous phenomena, yet they cannot show how phonological systems fit together. SPE mainly focuses on how to rewrite rules in the form of $\mathrm{A} \rightarrow \mathrm{B} / \mathrm{C} \_\mathrm{D}$, to show that $\mathrm{A}$ turns into $\mathrm{B}$, when it is preceded by $\mathrm{C}$ and followed by D. Therefore, SPE theory of phonology applies a certain process to the input to produce a certain output (McCarthy, 2008, p.1). Thus, "[r]ewrite rules apply in a serial fashion with the output of one rule being the input for the next rule, and so forth until the final output is produced. But the problem with rewrite rules of this type is that they are 
mainly descriptive rather than analytical". In other words, rules cannot explain the constraint upon which these rules are selected as the suitable ones to be applied to a certain case, and they cannot explain the circumstances upon which a certain rule is applied or blocked. Hence, OT was formulated to solve these problems (Elramli, 2012, pp.36-37).

\subsection{The Mechanism of Optimality Theory}

Since OT was regarded as an extension of generative phonology, it maintains the distinction between underlying and surface levels of representation, but through a different perspective (Honeybone, 2009, p.146). OT differs from other phonological theories, which depend on using rules. It aims to solve the problems which generative grammar faced. This refers to the fact that "[r]ewrite rules can describe lots of phenomena, but they do a poor job of explaining how phonological systems fit together". Therefore, instead of making rules for each language based on a set of observations, OT aims to formalize universal 'tendencies'. These tendencies are called 'constraints'; they form the most fundamental part of the theory (McCarthy, 2008, p.1).

\subsubsection{Basic Components of OT (Gen. with its candidate set, Con., and Eval.)}

OT has three basic components: Gen. or 'Generator' with a candidate set, Con., or 'constraint', and Eval. or Evaluation. It considers these components universal.

\subsection{1.a. 'Generator' (Gen.) and Candidate Set}

'Generator' or Gen. is the first component of OT. The role of the Gen. is to produce an infinite number of alternative output forms, from which the optimal real pronounced one is selected by a grammar. This collection of alternatives is termed a 'candidate set' (Prince \& Smolensky, 2002, p.4). McCarthy (2008) points out that "the list of possible outputs supplied by GEN for a given input is called the candidate set for that input". He adds that most of these candidates are ungrammatical, in which none of them is the real or the optimal one except one. He elucidates that the ability of Gen. to form an infinite number of candidates is referred to as 'freedom of analysis' in which any amount of structures is posited. Thus, Gen. can carry out a variety of operations on the inputs (p.17). He elucidates the relation between the input, GEN, and the candidates set in the following equation: 


\section{Partial flowchart for OT}

$$
\text { /input/ GEN } \rightarrow\{\text { cand } 1, \text { rand } 2, \ldots .\}
$$

\subsection{1.b. 'Constraint (Con.)}

Con. is the second and most prominent component upon which the theory is based. Every constraint is universal, i.e. it is the same in every language. Archangeli (1997) demonstrates that:

[c]on, as a universal set of constraints, is posited to be part of our innate knowledge of language. ... This assumption leads directly to a characterization of the universal aspects of human language: all languages have access to exactly the same set of constraints. This is the formal means by which universals are encoded. (p.15)

Hence, he highlights that there are no language-specific restrictions or constraints put on the input forms, every grammar can handle every possible input. Yet, the difference between the language grammar systems is the determination of the optimal output form. Prince and Smolensky (2002) confirm that although constraints are universal, the ranking of constraints is specific to every language (p.4).

Prince and Smolensky (2002) further postulate that these constraints are always in conflict with each other, and as a result, there are "winner constraints" and "loser constraints". The winner dominates the loser and is ranked over it. Thus, a constraint is 'violated' in order to fulfill another constraint at a higher level, and a ranking of a constraint set is created, i.e. 'a constraint dominance hierarchy'. This constraint dominance hierarchy evaluates a set of generated output candidates and determines the most 'optimal' output among them. The winner or the optimal output is the real pronunciation in the language (pp.3-4).

OT, consequently, depends on the ranking of constraints of a specific language to determine the optimal candidates in this language. Some constraints are ranked in a higher position than other constraints. Those high-ranked constraints are "more important and their violations are more costly". Hence, "a candidate violating a higher-ranked constraint incurs a more serious or costly violation than a candidate violating a lower-ranked constraints". The mechanism of OT, thus, relies on comparing the candidates to each other and evaluating these candidates "in terms of "costs" of their violations". Therefore, the optimal candidate 
is the "one whose violations are the least costly" (Peng, 2013, pp.240241). Accordingly, in OT:

Given two candidates, A and B, A is better than B on a constraint if $\mathrm{A}$ incurs fewer violations than $\mathrm{B}$. Candidate $\mathrm{A}$ is better than $\mathrm{B}$ on an entire constraint hierarchy if $\mathrm{A}$ incurs fewer violations of the highest-ranked constraint distinguishing $\mathrm{A}$ and $\mathrm{B}$. A is optimal in its candidate set if it is better on the constraint hierarchy than all other candidates. (Optimality phonology, 2008, n.p.)

According to McCarthy (2008), the contradiction between the input form and the output form is "a representational case where a new constraint is required". He illustrates that:

OT is a theory of constraint interaction, not a theory of constraints. OT itself does not say much about constraints except that they are universal and limited to markedness and faithfulness. OT requires a theory of constraints, $\mathrm{CON}$, but OT offers only minimal guidance about the theory. ... This means that the analyst must occasionally be a theorizer about CON as well. (p.166)

De Lacy (2010) also explicates "I wish I could list all the phonological constraints that exist in the human brain here. Unfortunately, there is no agreed-upon list. Many constraints have been proposed, and many algorithms too" (p.19). For convenience, a full examination of the basic types of cons and their ranking is presented after delimiting the other components of OT.

\section{$\underline{\text { 1.2.1.c.'Evaluation' (Eval) }}$}

The third component of optimality theory is called Eval. It is responsible for choosing the optimal candidate with respect to a ranking of Con. (See section1.2.4). McCarthy (2008) delimits that "Eval's job" is "to find the optimal candidate". It determines which of the infinite candidates will be assessed as optimal. It performs this task by "applying a language particular constraint hierarchy to the set of candidates" (p.19). Prince and Smolensky (2002) explain the criterion upon which the optimal candidate is chosen as:

[G]iven a grammar, a complete ranking of Con., we say that candidate $\alpha$ is more harmonic than or better than candidate $\beta$, if $\alpha$ is 
preferred by the highest-ranking constraint that distinguishes $\alpha$ from $\beta$. A candidate $w$ is optimal, if it is better than every distinct alternative candidate. (p.4)

The following Flowchart explains the role of Eval in OT:

\section{Eval [output] \\ /inpet/ Gen $\quad\{$ cand1, cand2,... $\} \rightarrow$}

\subsection{1.c.i. Tableau}

(McCarthy, 2008, p.19)

OT aims to evaluate output forms rather than input forms; hence, it is a "non-derivational linguistic model". It depends on the application of constraints to an input, and compares it with its output; thus, it is a "comparative" theory rather than a "derivational" one (McCarthy, 2002, p.3). McCarthy (2008) explains that the evaluation process is illustrated by means of a 'tableau'. In the tableau, the input form is placed on the top row of the tableau on the leftmost position, followed by the constraints. The candidates are placed in the leftmost column in cells just under the cell of the input form. One of these candidates is selected as the actual output form. It is placed first and indicated by a pointing finger or an arrow. The constraints are ranked from the highest to the lowest one and the ranking of these constraints is "encoded with the left-to-right order".

In addition, McCarthy (2008) elaborates that an asterisk is used to indicate a violation of some constraints; and an exclamation mark is used to refer to a "fatal violation". Fatal violation denotes the violation of an already obeyed constraint by the optimal output form, as represented in the following tableau. Each row displays the number of violations for a given candidate and constraint. Furthermore, shading is another annotation in the tableau; it is used to refer to a constraint that is irrelevant to the optimal output. Shaded cells indicate the constraints that do not have an effect on the actual pronounced output as "the competition has been decided by higher ranking constraints". These shaded cells "can contain violation marks or not". Thus, they can be "in both loser rows and winner rows". Hence, many writers abstain from using it (pp.43-45).

McCarthy (2008) further illustrates that there are two main types of tableaux, violation tableau and comparative tableau. The original tableau is the violation tableau. It focuses on constraint violations, while comparative tableau focuses on favoring relations (pp.43, 45). Violation tableau is benficial for determining which member of a given candidate set is the winner under different rankings of a given set of constraints. 
Prince and Smolensky (1993) illustrate this procedure through the following tableau:

Violation tableau

\begin{tabular}{|c|c|c|}
\hline $\begin{array}{l}\text { Candidates } \\
\text { form } \\
\text { /input/ }\end{array}$ & $\mathrm{C} 1$ & $\mathrm{C} 2$ \\
\hline${ }_{\mathrm{w}}$ & & $*$ \\
\hline $\mathrm{Z}$ & $* !$ & \\
\hline
\end{tabular}

The table displays two candidates (w) and $(\mathrm{z}) . \quad(\mathrm{w})$ is prefered to $(\mathrm{z})$, as it is the optimal and the real pronounced output form. It is indicated by the pointing finger. As a result, (w) is better than (z) on an entire constraint hierarchy, as it obeys the highest-ranking constraint. Once a candidate violates the highest-ranking constraint obeyed by the optimal candidate, it is marked in the tableau by an exclamation mark, to indicate fatal violation. The constraints hierarchy is shown in the following equation: $\mathrm{C} 1>\mathrm{C} 2$ or $\mathrm{C} 1$ outranks $\mathrm{C} 2$. Such ranking is represented by setting the constraints from the left to the right starting with the highest-ranking constraint till the lowest one (p.118).

Some candidates may have "the same number of violations", so they cannot distinguish between the optimal candidate and the other candidates (Prince \& Smolenskey, 2002, p.4). Thus, there is no ranking between the competing constraints. This is called a"harmonic bounding" between the two candidates: the real optimal one and the ungrammatical one (De Lacy, 2007, p.11). McCarthy (2008) explains "harmonic bounding by saying that: "if candl has a proper subset of cand2's violation marks, then cand 2 cannot beat candl under any ranking of the constraints in that tableau. We then say that cand2 is harmonically bounded by candl under that constraint set". Thus, in order to solve this problem, the analysis "requires introducing a constraint that breaks the bounding relation by favoring the winner over the loser that threatens to bound it". He adds that "harmonically bounded candidates cannot win under any ranking, it is predicted to be impossible in any language, if all relevant constraints have been considered" (pp.80-82).

The comparative tableau has the same schema, but with slight differences. In the comparative tableau, for each losing candidate in the tableau, each constraint is examined to judge "whether it favors the 
winner over this loser (W), or favors this loser over the winner (L) ... The $\mathrm{W}$ and $\mathrm{L}$ symbols are entered into the corresponding cells of the tableau". They indicate "the function of the constraint in the system". Thus, every cell in a loser row has symbols $\mathrm{W}$ and $\mathrm{L}$ "because they represent how a loser compares with the winner on each constraint". In addition to these two main types, another type of tableau is introduced. It has been revealed that it will be "difficult to fill in the Ws and Ls of a comparative tableau without first constructing a violation tableau". Therefore, "the combination tableau" is introduced. It includes both "violations as well as the W and L annotations" (McCarthy, 2008, p.46). In this paper, the researcher follows classical OT in line with Al-Hashimi (2004). She chooses to follow the original (classical) tableau which is the violation tableau, as the number of violations reflects the competition between the different constraints. Consequentely, it differentiates between the winner and the losers.

Moreover, the ranking of the constraints can be displayed by a Hasse diagram, which shows an ordered set in which nodes are elements, and arrows indicate the order relation between elements (your dictionary, n.d.). The following Hasse diagram illustrates the constraints ranking in the previous tableau:

\section{Constraint 1}

Constraint 2

Elramli (2012) sums the basic architecture of OT as follows:

$$
/ \text { Input } / \rightarrow \text { Gen } \rightarrow\{\text { cand1, cand2, } \ldots \text { candn }\} \rightarrow \text { Eval } \rightarrow \text { [output }]
$$

To recapitulate, unlike generative grammar, OT aims to present a phonological system in terms of a set of violable and ranked constraints. It has three basic components: Gen. with a candidate set, Con. and Eval. Con. or Constraint is universal. OT has two essential kinds of constraints: faithfulness (F) and markedness constraints (M), which are always in conflict with each other, and such conflict creates 'a constraint dominance hierarchy'. OT states that each language has its own rules, but all languages share the same set of constraints. Nonetheless, what differs from one language to another is its ranking of constraints according to their importance, as would be discussed in the following sections. As for Gen. or generator, it produces a list of possible outputs (candidate set) 
from which the optimal output is chosen. Finally, Eval. or evaluation chooses the optimal candidate, a process which is illustrated by a tableau.

\subsubsection{Basic Types of Constraints in OT: (Faithfulness Constraints (F) and Markedness Constraints (M))}

Prince and Smolensky (2002) affirm that, as a result of following generative phonology which distinguishes between underlying forms and surface forms, constraints have two basic types: faithfulness constraints and markedness constraints. Besides, OT observes closely obligatory contour principle (OCP) (see the section 1.2.3). Archangeli (1997) illustrates that unmarked properties are the properties, which are found in all languages, while marked properties are those that belong to a specific language. Thus, the more universal a property is in a particular language, the less marked it is. Therefore, OT can determine the "universals" and the particulars "markedness" (p.3). Under OT, unmarked properties are indicated by faithful constraints, while marked properties are indicated by markedness constraints. In spite of the fact that both faithfulness and markedness constraints are universal, yet, "such knowledge must be accompanied by an understanding of which constraints a language favors most and which constraints are of less importance" (Btoosh \& Bin Talal, 2006, p.196). Section (2) displays some of the Arabic faithfulness and markedness constraints used in this study.

McCarthy (2007) justifies that, on the one hand, faithfulness constraints are very "conservative"; they are the constraints that require identity between the input forms and the output forms. On the other hand, he clarifies that markedness constraints are those which impose requirements on the structural well-formedness of the output in each language. Consequently, faithfulness and markedness constraints are always in 'tension' with each other. However, he adds that a conflict between two markedness constraints or between two faithfulness constraints is also possible (pp.1-5). Btoosh and Bin Talal (2006), in the following tableau, examplify the mechanism of OT and the conflict between two (faithfulness and markedness) constraints: Onset (M) (every syllable should have an onset) and Dep-IO (F) (no epenthesis), using the Arabic name /afmad/:

\begin{tabular}{|c|c|c|}
\hline Input:/afmad/ & Onset (M) & Dep-IO (F) \\
\hline a. & & $*$ \\
\hline
\end{tabular}




\begin{tabular}{|c|c|c|}
\hline ['a̧mad] & & \\
\hline b. [afmad] & $* !$ & \\
\hline
\end{tabular}

The table illustrates that candidate (a) is the optimal output. It obeys Onset $(\mathrm{M})$ in which a glottal stop is added at the beginning of the syllable. Nevertheless, (a) violates Dep-IO (F), as an extra sound is added in the output. Moreover, (b) exhibits fatal violation, as it violates the highest ranked con. (Onset (M)), already obeyed by (a) or the optimal output, as indicated by the empty cell. Consequently, Onset (M) dominates and is ranked over Dep-IO (F), i.e. Onset (M) > Dep-IO (F) (p.197).

\subsubsection{Obligatory Contour Principle: OCP-total, OCP-place, and OCP-manner}

OCP or Obligatory Contour Principle refers to the prohibition of adjacent and identical sounds (Buckley, 1997, p.26). OCP or OCP-total reveals that "a sequence of two X's is prohibited" (Suzuki, 1998, p.27). Thus, it reduces adjacent segments that are identical (Buckley, 1997; Mustafawi, 2011). McCarthy (1988) highlights that OCP "ensures that a geminate consonant like $/ \mathrm{pp} /$ is represented as a single segment from a featural standpoint" (p.88).

Boersma (1998) displays another example that "if a morph ending in $/-\mathrm{m} /$ is concatenated with a morph starting with $/ \mathrm{m}-/$, the usual timing of syllable-crossing clusters will result in the long consonant [- $\underline{\mathbf{m} \mathbf{m}}-\mathbf{}$. Thus, "[t]he perceptual identity of one of its constituents is, therefore lost, violating featural faithfulness" (p.2). Furthermore, Berkley (1994) gives an English example on how to avoid identical consonants. When the adverbial suffix /-al/ is added to the word 'scale', /1/ in /-al/ is replaced by $/ \mathrm{r} /$, a consonant from the same lateral category. Consequentely, the word 'scale' is dissimilated into 'scalar' instead of '*scalal' (as cited in Van Goh, 2010, p.17). OCP-total, in this paper, is examined in the data in examples $(1,2$, and 3$)$.

McCarthy (1988) affirms that OCP is "also active between nonidentical segments sharing a feature". Thus, OCP-feature is generated; it specifies that two non-identical segments sharing one or more features are blocked (as cited in Van Goh, 2010, p.16). Suzuki (1998) adds that "the more similar the two elements are, the stronger the identity avoidance effect is" (p.17). Myers (1994) also formulates OCP feature as: 
"[t]wo identical specifications must not occur in the same domain" (p.27). Likewise, Boersma (1998) delimits that "[a] feature value [F] should not appear twice inside a specified domain" (p.10). Hence, Steriade (1995) interprets OCP as a constraint against the repetition of a feature. Furthermore, Pierrehumbert (1993) reports that "in Arabic the OCP effect is gradient corresponding to the proximity between the two segments" (as cited in Suzuki, 1998, p.20). Moreover, Mustafawi (2011) proves that OCP is applied to Qatari Arabic, i.e. it "is subject to proximity and to a gradient similarity effect" (p.230).

Van Goh (2010) clarifies that OCP-feature can be catergorized according to the three features [place], [manner], and [voice]. Consequentely, OCP-feature is divided into OCP-[place], OCP-[manner], and OCP-[voice]. He illustrates that OCP-feature uses "natural classes instead of single features", where a natural class is "a set of segments with a feature shared by all members of that class (p.22). In (1968), Chomsky and Halle assume some kinds of feature system and take these features to be the smallest building blocks of phonology. Hence, each Segment consists of bundles of features, or feature matrices, e.g., [+nasal], [-nasal], [+sonorant], [-sonorant], [+ coronal], [-coronal] etc (p.87).

OCP-[place] is applied to "non-identical consonants of the same place of articulation" (Buckley, 1997, p.26). Boersma (1998) elucidates that one of the OCP functions is "simply the tendency not to repeat the same articulatory gesture: an articulatory *REPEAT constraint" (p.2). In other words, if $\mathrm{x}$ and $\mathrm{y}$ share the same place feature within the same natural class, the combination [xy] is prohibited. The following are four natural classes classified according to the primary place of articulation: (1) labials (labial and bilabial) (2) coronals (dental, alveolar, alveopalatal, palatal), (3) dorsals (velar and uvular) and gutturals (laryngeal and pharyngeal) (Colavin, Levy \& Rose, 2010; Clements, 2000). As a result, OCP-[place] is sub-divided into OCP-[+labial], OCP-[+coronal], OCP-[+dorsal] and OCP-[Guttural] (Van Goh, 2010, pp.21, 29). However, OCP-[Guttural] is not considered in this paper.

OCP-[+labial] refers to the prohibition of two successive labial sounds (see examples 4, 14, 16 in the analysis). Labial sounds are the sounds which are articulated by one or both lips. As for OCP-[+coronal], it disallows the adjacency of two coronal sounds (examples 5, 6, 8, 9, 10, 12,13 in the data). A coronal sound is "formed by raising the tip or blade of the tongue towards the hard palate". Finally, OCP-[+dorsal] prevents the existence of two adjacent dorsal sounds (see example 11). Dorsal 
consonants are articulated with the back of the tongue (the dorsum) (Revolvy, n.d.; Van Goh, 2010; English Oxford living dictionary).

OCP-[manner] dictates that two adjacent sounds that share the same manner feature are prohibited. Some features that specify the manner of articulation are: [sonorant], [nasal], and [lateral]. In other words, if $\mathrm{x}$ and $\mathrm{y}$ share one of these manners of articulation, the combination of [xy] is blocked (Van Goh, 2010, p.21). Consequently, OCP-[manner] has such sub-classes like OCP-[+sonorant] which avoids the sequence of two sonorants $(/ \mathrm{l} /, / \mathrm{r} /, / \mathrm{n} /, / \mathrm{m} /, / \mathrm{y} /, / \mathrm{w} /)$ (Van Goh, 2010; Goodman, n.d). Chomsky and Halle (1969) define sonorant sounds as "sounds produced with a vocal tract cavity configuration in which spontaneous voicing is possible". They add that "vowels, glides, nasal consonants, and liquids are sonorant" (pp.301-302).

Cohn (2014) demonstrates that "sonority characterizes the behavior of sounds in syllable structure and many other aspects of phonological patterning (p.79). Parker (2016) also mentions that sonority "is correlated with loudness" (n.p.). This means that "(t)he more sonorous a sound is, the louder it will tend to be, and conversely, less sonorous sounds involve greater air pressure (and concomitant rate of air flow)" (Parker, 2002, p.2). Furthermore, Goodman (n.d.) refers to Dresher (1989) who explains that OCP in Arabic is conditioned by the feature of sonority (p.41). The current paper similarly proves the effect of sonority in the LHQ (see examples 7, 8, 9, and 10).

Additionally, OCP-[+nasal] disallows the sequence of two nasals $(/ \mathrm{m} /$ and $/ \mathrm{n} /)$ (see example 7). Chomsky and Halle (1968) define nasal sounds as sounds which "are articulated with a lowered velum which allows the air to escape through the nose" (p.316). As for OCP[+lateral], it prevents the adjacency of two lateral sounds $(/ \mathrm{l} /, / \mathrm{r} /)$ (see example 8). Chomsky and Halle (1968) point out that "[1]ateral sounds are produced by lowering the mid section of the tongue at both sides or at only one side, thereby allowing the air to flow out of the mouth in the vicinity of the molar teeth" (p.317). Thus, it denotes diverting the airstream towards the sides of the tongue. In sum, the examined Cons. of OCP in this paper are: OCP-total, OCP-[place], and OCP-[manner]. However, OCP-[voice] lies beyond the focus of this paper.

\subsubsection{How to rank constraints}

McCarthy (2008) explains that ranking constraints is based on the "priority relationships among constraints" in which the higher-ranking 
constraints are ranked over the lower-ranking ones. This constraint ranking is a result of the conflict between constraints. He adds that there are three essential elements of any valid ranking argument: constraint conflict, a winner-loser comparison, and no other constraint that could do the same job, as explaine in the following:

(i) A conflict between two constraints is initiated. They disagree with their assessment of a pair of competing output candidates derived from the same input. Constraints that are violated by both candidates can also conflict, as long as there is disagreement about which candidate each constraint favors (p.41).

(ii) One member of this pair of competing candidates must be the actual output form for the given input. It is the winner candidate. The constraint that favors the winner must dominate the constraint that favors the loser. In other words, whenever a constraint favors a winner over some losers, there is a higher-ranking constraint that favors this winner over these losers. The winner is better than all of the losers, but we have no evidence about whether any loser is better than any other loser (pp.41, $42,46)$.

(iii) No disjunction: The ranking argument is secure only if there is no third constraint that could also be responsible for the winner beating the loser. In other words, Con 1 must dominate Con 2 only if there is no third constraint Con 3 that could be doing the same work as Const1 (p.42).

He further illustrates that the ranking argument starts with formulating a descriptive generalization which hints at which constraints are involved in the analysis. Then, a conflict between a set of constraints is generated: higher-ranking constraints that favor the winner over that losers and lower-ranking constraints that favor some losers. The winner is already known, because it is the actual pronunciation and the data of that language and the analyst is trying to figure out which ranking will produce that winner. The ranking argument is solid precisely, because no other constraint does the job (pp.46-57).

McCarthy (2008) also highlights the fact that it is easier to begin the ranking process with a faithfulness violation, as any faithfulness violation must be compelled by a higher-ranking markedness constraint. In other words, each violated faithfulness constraint is dominated by one or more markedness constraints. Furthermore, he clarifies that some 
constraints favor neither a winner nor a loser and they do not affect the ranking argument. Thus, these constraints should not be included in the tableaux (pp. 38, 55, 57).

\subsubsection{Types of Constraints Ranking}

Prince and Tesar (2004) demonstrate that OT grammar is mainely defined by rankings of constraints in which each constraint dominates the other (p.130). Under this hypothsis, OT has two kinds of ranking, "Total ranking" or "Strict ranking" and "Stratified ranking". "Total ranking" or "Strict ranking" ascertains that "[o]ne violation of a higher-ranked constraint is worse than any number of violation of a lower-ranked constraint". In other words, each constraint has to be ranked relative to every other constraint (Rules and Constraint, n.d., p.6). Tesar (2000) illustrates that a "hierarchy with only one constraint in each stratum is called a total ranking" (p.602). The "Total ranking" or "Strict Ranking" is represented in the following tableau:

\begin{tabular}{|c|c|c|}
\hline$/ \mathrm{x} /$ & $\mathrm{A}$ & $\mathrm{B}$ \\
\hline$[\mathrm{y}]$ & $* !$ & \\
\hline$[\mathrm{z}]$ & & $* *$ \\
\hline
\end{tabular}

The table exhibits that

"constraint A strictly outranks constraint B". Thus, A dominates B and is ranked over it. As there is a domination relation between $\mathrm{A}$ and $\mathrm{B}$, each stratum or level has only one constraint. Consequentely,"all constraints are strictly ranked" (Rules and Constraint, n.d., p.6). McCarthy (2008) elucidates that this strict ranking of constraints is presented by solid lines. Thus, these solid lines are "indicator of constraint interaction" (p.32).

However, strict ranking is not usually established (McCarthy, 2008, p.48). Hence, "Stratified ranking" has been introduced. It is another type of constraints ranking which "consists of ranked strata, where each stratum contains one or more of the constraints". Therefore, the resulting hierarchy has constraints that "are in the same stratum, neither dominating the other" (Tesar, Grimshaw \& Prince, 1999, p.21). Tesar (2000) emphasizes that "[t]he domination relation is not defined for some pairs of constraints". Hence, "[a] stratified hierarchy consists of ranked strata in which each stratum contains one or more of the constraints" (p.602). As a result, constraint hierarchies "can be partial orderings" (McCarthy, 2008, p.122). 
Moreover, McCarthy (2008) clarifies that in real analyses, a total ordering of the constraints cannot usually be established. In OT, the process of analysis can lead to a partial ordering in which both Con1 and Con 3 dominate Con2, and the ranking between Con 1 and Con 3 is unknown. The analyst cannot determine rankings for which there is no support or evidence. Consequently, a disjunction between Con 1 and Con 3 occurs. Their ranking with respect to one another is unknown and perhaps unknowable, based on data from that language. They are called unviolated constraints. These unviolated constraints can never be ranked with respect to one another, as the winner violates neither of these constraints. Hence, they are not in a conflict with each other, and there is no one constraint that dominates the other, thus, unviolated constraints are undominated. Such ranking is represented graphically using a Hasse diagram. In tableaux, it is usually indicated by drawing a broken line between columns with unranked constraints (pp.43, 48, 49, 60). In line with Al-Hashimi's assumption, the researcher uses dotted line between constraints to indicate that they are equal.

Tesar, Grimshaw, \& Prince (1999) comment that "[t]his freedom to have hypotheses that aren't totally ranked is important to the success of the algorithm" (p.21). Prince and Tesar (2004) figure "Stratified domination hierarchy" in the following form:

$$
\{1,2, \ldots, 3\}>\{4,5, \ldots, 6\}>\ldots>\{7,8, \ldots, 9\}
$$

It displays that constraints con 1, con 2, and con 3 have no ranking, where equally ranked constraints are presented by a "comma" between them. Moreover, such cons are equally ranked in the same stratum; they are equally weighted in the computation of harmony. Therefore, con 1, con 2 , and con 3 dominate all the remaning constraints, and the same is true for constraints con 4 , con 5 , and con 6 . They are not ranked with respect to each other, but they all dominate the lower constraints, con 7 , con 8 , and con 9 , in the following stratum. tableau:

Topintzi (n.d) further illustrates stratified ranking in the following 


\begin{tabular}{|r|l|l|}
\hline a. Cand1 & & \\
\hline b. Cand2 & & \\
\hline
\end{tabular}

The previous tableau displays that both constraint 1 and constraint 2 are at the same level or stratum, as indicated by wavy line to reveal "equality in rankings". Then both of them outrank C3, i.e. C1, C2 > C3 (p.4). However, in this paper, following Al-Hashimi (2004), the researcher uses dotted lines to show that the two constraints do not dominate each other, and that they are at the same rank.

\subsubsection{Previous Studies}

Applying the theory of OT as a framework to analyze Arabic phonology, either Classical Arabic or Colloquial Arabic, was considered by some studies. On the one side, a study concerning Classical Arabic was conducted by Al-Hashimi (2004) in her M.A thesis The Phonology of nasal $n$ in the Language of the Holy Qur'an. This study examined all the tajweed rules in which the $/ \mathrm{n} /$ sound is involved. On the other side, other studies, in which OT was used to examine some Arabic dialects, include Elramli (2012) in his $\mathrm{PhD}$ dissertation Assimilation in the phonology of a Libyan Arabic dialect: A constraint-based approach. He used a constraint-based framework (OT) to investigate some assimilatory processes in Misrata Libyan Arabic (MLA).

In addition, Mustafawi (2011), in his paper "The OCP as a synchronic constraint in Arabic", displayed analyses for the OCP (Obligatory Contour Principle) as a constraint in the grammar of Qatari Arabic. As for Youssef (2013), in his dissertation Place Assimilation in Arabic: Contrasts, Features, and Constraints, he provided descriptions of all instances of place of assimilation in two dialects: Cairene and Baghdadi Arabic. Finally, Btoosh and Bin Talal (2006), in their paper "Constraint Interactions in Jordanian Arabic Phonotactics: An Optimality-Theoretic Approach", presented a constraint-based analysis of Jordanian Arabic phonotactic rules within the OT framework.

Having explained the basic components of OT and the ranking of cons, and previous studies, the ensuing sections elaborate on chosen constraints and principles that would be examined in LHQ in the current study. 


\section{Part 2}

\subsection{Selected Constraints in $L H Q$}

1-Ident-IO faithfulness constraint: segments have identical values of feature $\mathrm{F}$ in the input form and the output form, i.e. "the value of [voice] ...(is) the same in input and output" (Honeybone, 2009, p.146). Matar (2005) explains that assimilation in the English past verb "liked" may have some alternatives, it may be [laikt], [laikd]*, or [laikid]*. The real pronounced one is [laikt] (p.3). Under OT, it is noted that this choice violates the Ident-IO (F) constraint, because /d/ does not retain its properties. This entails that a/d/ sound which has [+obstruent] and [+voiced] features in the input form turns to be a /t/ sound, which has [+obstruent] and [-voiced] features in the output form, i.e. it loses its voicing. Hence, the input form is not identical to the output form. This constraint is highly observed in the process of Al-'IZhaar (see section 3.7).

2- Max-IO (F) (Maximality): every segment in the input has an output correspondent and nothing is deleted (Honeybone, 2009; Bin, 2010). For example, the English noun 'dog'/dog/ may have some alternatives, e.g. [dog], or *[do]. The optimal one is [dog], thus, [dog] obeys Max-IO (F) in which each sound in the input is realized in the output (Pindziak \& Witty, 2011, p.89). It is noted that Max-IO (F) also seems to be powerful in LHQ. For example, in the assimilation process of the $/ \mathrm{n} /$ sound, $/ \mathrm{n} /$ is not deleted, but it is always replaced by other segments. It may be replaced by a geminated consonant ('Idghaam), an allophone ('Ikhfaa'), or another nasal (/m/) (Iqlaab). Therefore, Max-IO (F) is powerful enough to outrank other faithfulness constraints in LHQ (Al-Hashimi, 2004, pp.55-56).

From Max-IO (F), Max-IO (Feature) (F) is constructed. McCarthy (2008) expounds that "featural atoms can exist independently of the segmental molecules" (p.200). Consequently, Max-IO (Feature) (F) shows that a feature of a segment in the input form has a correspondent in the output form. One example of Max-IO (Feature) (F) is Max-IO (Nasal) (F); it stresses that "[t]he feature nasal from an input segment is realized in the output" (Davis \& Shin, 1999, p.290). For instance, in the English word "incapable", the $/ \mathrm{n} /$ assimilates into the following $/ \mathrm{k} /$ to form [ $\mathrm{\eta}]$. Thus, the nasal feature is retained in the output form (Neijt, 2002, p.21). Another example of Max-IO (Feature) (F) is Max-IO (Emphatic) in which "[e]very feature [Emphatic] of the input has a correspodent in the output", e.g., the rightward emphatic spread in the 
Arabic word /sabaaf/ 'morning' (Watson, 1999, p.291), in which the emphatic feature is kept in the output. Another example is /'i $\mathrm{i}$ Zalamu/

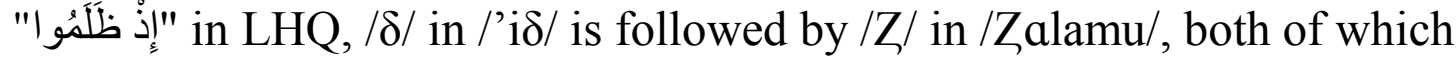
are inter-dental sounds. Thus, $/ \delta /$ assimilates completely into /Z/, and /'i $\delta$

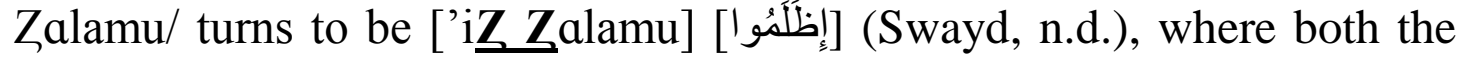
symbols and the transcription are provided by the researcher.

3- Complex *(XYZ) (M) is a universal markedness constraint. It proclaims that "a syllable internal consonant cluster is not allowed". In other words, a sequence of two or more specific consonants in a syllable is not allowed (kim, 2002, p.83). For example, in Egyptian Colloquial Arabic, the two words /taft rigleek/ turn into [taft-i-rigleek] 'under your legs', in which the [i] vowel is added in order to prevent a sequence of three consonant sounds (Salem, 2005, p.78).

In LHQ, this constraint refers to the prohibition of a certain sequence of sounds. The following constraints are derived from complex *(XYZ) (M) and they are used in LHQ. *Son.Gem (M) avows that a gemination of two sonorant sounds $(/ \mathrm{l} /, / \mathrm{r} /, / \mathrm{m} /, / \mathrm{n} /, / \mathrm{y} /, / \mathrm{w} /)$ is prohibited. *VV.Semi-vowel (M) is another constraint in which the sequence of a long vowel followed by a semi-vowel is blocked. Moreover, *Nas (N).Lateral (M) refers to the prohibition of the combinations of the sonorant $/ \mathrm{n} /$ followed by one of the lateral sounds $/ \mathrm{l} /$ or $/ \mathrm{n} /: *[\mathrm{nl}]$ and $*[\mathrm{nr}]$, while *Lateral.trill $(\mathbf{M})$ decrees that the sequence of $/ \mathrm{l} /$ followed by $/ \mathrm{r} /$ is not allowed. As for *Lateral.Solar sound (M), it indicates the blocking of the sequence of $/ 1 /$ followed by one of the solar sounds; $/ \mathrm{t} /$, $/ \mathrm{d} /, / \mathrm{z} /, / \mathrm{s} /, / \delta /, / \theta /, / \mathrm{Z} /, / \mathrm{s} /, / \mathrm{d} /, / \mathrm{r} /, / \mathrm{J} /, / \mathrm{t} /, / \mathrm{n} /$, and $/ \mathrm{l} /$. In addition, the sequence of $/ \mathrm{n} /$ followed by $/ \mathrm{s} /$ is prohibited $*[\mathrm{~ns}]$, and the combination of the two sounds $/ \mathrm{q} /$ and $/ \mathrm{k} /$ is also not allowed in Hafs recitation $*[\mathbf{q k}]$. Finally, the sequence of $/ \mathrm{m} /$ and $/ \mathrm{b} /$ sounds is banned, *[mb] (Adopted from Al-Hashimi, 2004; Swayd, n.d.; An-Nabulsi, 2008, Abdel-Hameed, 2007). All these constraints are examined throughout the analyses in this study.

4- Onset-position (M): In this markedness constraint, a consonant in syllable initial position must be considered stronger than a consonant in syllable final position. In other words, "[p]honological processes show that syllable-initial position is the strongest position" and "is universally stronger than syllable-final position". For example, in CA, based on this 
assumption, Sibawayh (n.d.) considers the direction of Al-'Idghaam as "basically regressive". He justifies that "the relative positional strength of an element determines the direction of assimilation in the combination". Thus, "in the combination the stronger second segment will dominate the weaker first one"(as cited in An-Nasser, 1985, pp.105-106).

5- Share f (M): According to this markedness constraint,"if a segment bears the feature-value $[\mathrm{F}]$, then the immediately preceding/following segment must bear that feature value (Bakovic 2000; Eisner 1999; Lombardi 1995/2001; Pulleyblank 2004)" (as cited in McCarthy, 2011, p.2). Ibn Ginni ( $4^{\text {th }}$ century) also declares that neighboring sounds or adjacent sounds take features from each other (as cited in An-Nasser 1985, p.130). For example, in English, /n/ assimilates to the place of articulation of the following consonant, e.g. /in - possible/ becomes [impossible] in which $/ \mathrm{n} /$ shares with $/ \mathrm{p} / \mathrm{a}$ [+labial] feature, thus, it turns to [m] (Stockwell \& Minkova, 2001, p.110).

6- Obligatory Contour Principle: OCP-total, in addition to all the sub-classes of OCP-place and OCP-manner, strongly appear in LHQ. This principle has been explained above, yet, in this section it is clarified in relation to the LHQ. OCP-total could be inferred from what Sibawayh (n.d.) proves that when two identical sounds are adjacent to each other, it will be easier for the speaker "to execute only one action of the tongue to produce the two identical segments (Vol. 3, p. 530)" (as cited in An-Nasser, 1985, p.108). Furthermore, Sibawayh (n.d.) elucidates that in 'Idghaam Al-Mutajaanisayn in LHQ, two adjacent sounds sharing the same place of articulation are blocked (OCP-place) (as cited in An-Nasser, 1985, p.112) (see section 3.3). Moreover, OCPmanner is also clear in LHQ as it strongly occurs in 'Idghaam AlMutaqaaribayn (see section 3.4). Hence, the following are to be addressed and inspected in this paper: OCP-total, OCP-[place]: OCP[+labial], OCP-[+coronal], and OCP-[+dorsal]; OCP-[manner]: OCP-[+sonorant], OCP-[+nasal], and OCP-[+lateral].

Having explained the selected constraints which concern the application of OT on Arabic, the coming sections display the three chosen Tajweed rules.

3.0. The three Tajweed rules of Al-'Idghaam, Al-'Ikhfaa', and Al'iZhaar 
Abdel Hameed (2009) affirms that every two adjacent sounds have a relation to each other; they may be identical sounds, similar sounds, proximal sounds, or completely different sounds. As a result of these different types of adjacency, different rules as Al-'Idghaam, Al-'iZhaar, and Al-'Ikhfaa' are triggered (p.156).

\subsection{Al-'Idghaam or Assimilation in LHQ}

LHQ, as many other languages, has the most common phonological phenomenon, which is the assimilation process or Al'Idghaam. Muslims in general and quraa' (reciters), in particular, pay great attention to the use of assimilation. Arab linguists commenced their studies of assimilation processes from the early times of Islamic civilization. They refer to assimilation as "Al-'Idghaam". To them, it plays an important role in phonology and phonetics; as it may be accompanied by other phonological processes, e.g., nasalization or velarization (Alfozan, 1989, pp.50-51).

Eastern linguists, on the one hand, have their own contribution to the definition of assimilation. Al-Khalil Ibn Ahmed Al-Faraahidiy was the first Arab grammarian who used the term "Idghaam" in the sense of gemination. He stated that "gemination is an indication of 'Idghaam" (as cited in An-Nasser, 1985, p.105). Following Al-Faraahidiy, Sibawayh and Ibn Ginni investigated the assimilation phenomenon. They were pioneers in studying assimilation, and they called it "At-taqriib" (as cited in Rahim and Younis, 2013, pp.1-2), which means "taqaarub al-aswaat". In other words, sounds share their neighbors' characters (Alfozan, 1989, pp.50, 59).

Similarly, the majority of cases of assimilation discussed by Sibawayh (n.d.) is defined as "the fusion of two adjacent segments" (as cited in An-Nasser, 1985, p.105). Al-Jamzuuriy (1198 Ah) also explains that assimilation or Al-'Idghaam in the science of tajweed means "to insert or submerge one thing into another". It refers to the joining or the assimilation of two sounds (as cited in Abu Zayed, 2010, p.80). On the other hand, from western linguists' point of view, Windsor-Lewis (1969), Jones (1976), and Ellis \& Hardcastle (1999) define assimilation as the process of replacing one sound by another under the influence of a third sound. They agree that assimilation makes adjacent sounds more alike (as cited in Rahim and Younis, 2013, pp.1-2). 


\subsection{The different types of assimilation or Al-'Idghaam}

As noted above, assimilation or Al-'Idghaam in LHQ takes place due to two conditions. These conditions are: (1) the phonological characteristics of the two adjacent sounds whether they are two identical, similar, or proximal sounds, and (2) The distance between sounds whether they are within the same word or between two words. Therefore, both of these factors determine the different types of assimilation as well. They determine the following: (a) the direction of influence or whether it is a regressive or a progressive assimilation, (b) the degree of influence or whether it is a complete or a partial assimilation, and (c) whether assimilation is accompanied by nasalization or not (Abdel-Hameed, 2007; Alfozan, 1989).

1- The direction of influence: According to Alfozan (1989), sounds affect each other, and this may occur in one of the two directions (p.72). Thus, the direction of influence can lead to regressive or progressive assimilation. Sibawayh (n.d.) demonstrates that the stronger segment will dominate the weaker segment, thus, the factors of strength in the segments will play a significant role in determining the direction of the outcome of assimilatory processes, whether it is a regressive or a progressive assimilation (as cited in An-Nasser, 1985, p.106). As a result, being a regressive or a progressive assimilation process depends on the position of the stronger segment.

Regressive (or anticipatory) assimilation is defined as: "the sound changes because of the influence of the following sound" (Crystal, 2008, p.40). It is a "backward influence" in which "the preceding sound is influenced by the following one" (Alfozan, 1989, p.72). It indicates the influence of one sound on another sound, which immediately precedes it and changes it into the same sound. An example in CA is /'al.si.raat/, which becomes ['ass și.raat] "the Straight Way" (Al-Faatifah: 6), in which /1/ changes into /s/ (Rahim and Younis, 2013, p.5).

As for Progressive (or preservative) assimilation, it is defined as: "the sound changes because of the influence of the preceding sound" (Crystal, 2008, p.40). Consequentely, it is a "forward influence" in which a sound is affected by the preceding conditioning one (Alfozan, 1989, p.30). It shows the influence of a sound on another which immediately follows it and changes it into another sound, for example: /'idtaraba/ turns into ['idtaraba] (to be confused) (Alfozan, 1989, p.72). (اضْتَرَب اضْطَرَبَ) 
2- The degree of influence or whether it is a complete or a partial assimilation: Arab linguists classify assimilation on the basis of the degree of influence into two classes: complete (total) assimilation and partial assimilation (Rahim \& Younis, 2013, p.5). Assimilation can take place between two identical sounds in which the two assimilated sounds turn into one geminated sound, which leads to "complete assimilation". Yet, if assimilation is applied to "more alike" sounds, it leads to "partial assimilation", in which the assimilated sound leaves some of its features on the second one (Elramli, 2012; Alfozan, 1989), as in LHQ /'afattu/ which turns to be ['afatstu] "encompassed [in knowledge]" (An-Naml,

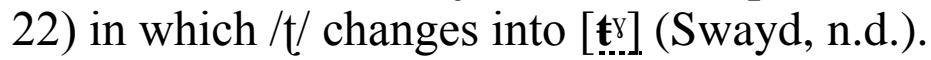

Sibawayh (n.d.) uses the term 'Idghaam for both partial and complete assimilation. Ibn Ginni (n.d.) follows Sibawayh's concept of 'Idghaam; he differentiates between two subtypes of 'Idghaam: "The lesser 'Idghaam" and "The greater 'Idghaam". "The lesser 'Idghaam" refers to all kinds and degrees of partial assimilation among the consonants, whereas the "The greater 'Idghaam" refers to complete assimilation between two neighboring consonants to produce a geminate (as cited in An-Nasser, 1985, p.105).

3- Assimilation with or without nasalization or ghunnah: Nasalization or ghunnah is defined as "a natural intrinsic characteristic" of the two sounds $/ \mathrm{m} /$ and $/ \mathrm{n} /$. Sibawayh (n.d.), Al-Jazariy (798Ah), and Al-Jamzuuriy (1198Ah) explain that the assimilation process may or may not be accompanied by nasalization depending on the nature of the assimilated sounds. Therefore, assimilation has two types: 'Idghaam with ghunnah (nasalization) (see examples 2, 3, 7 in the data) and 'Idghaam without ghunnah (see examples 1, 9, 10 in the data) (as cited in AbdelHameed, 2007; An-Nasser, 1985; Abu Zayed, 2010).

\subsection{Assimilation of two identical sounds or 'Idghaam Al- $\underline{\text { Mutamaathilayn }}$}

'Idghaam Al-Mutamaathilayn refers to "the combination of two identical sounds"; in which the first is saakin (Saamit) and the second is mutafarrik (Saa'it), and both have the same features and the same place of articulation (Read with Tajweed Rules, n.d). In other words, it is the meeting of two identical sounds, one of which is non-voweled (consonant) and the other is voweled (consonant followed by a short vowel). In addition, the two sounds are adjacent without a short vowel in between. Hence, the first sound is inserted into the second one and the 
result is one emphasized sound of the second type (Czerepinshki \& Swayd, 2000, p.52). Therefore, the result is a gemination of the second sound as the first sound leaves no trace on the pronounced one and the two sounds immediately follow each other; for example: /bal.la.hu/ turns to be [bal la.hu] 'but for him' (Alfozan, 1989, p.59).

Sibawayh (n.d.) justifies this type as follows: "because the two consonants are homorganic, speakers find it easier to execute only one action of the tongue to produce the two identical segments". Thus, he observes some changes in the place of articulation of the first sound, saying that the speakers "left their tongues from the outlet only once" (as cited in in An-Nasser, 1985, p.108). Consequently, Arabs prefer to apply 'Idghaam, in which the tongue goes to the place of articulation just once in producing the geminated form. Furthermore, Al-Jamzuuriy (n.d.) sums up 'Idghaam Al-Mutamaathilayn in his poem in the following lines:

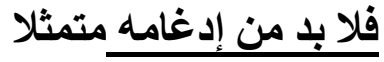

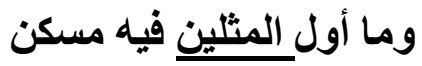

(kinz Al-Maৎaany)

He demonstrates that in this case, 'Idghaam is better than 'IZhaar between two identical sounds, hence, it is the optimal one.

\subsubsection{Analysis}

3.3.1. Assimilation of two identical sounds or 'Idghaam AlMutamaathilayn between two words without nasalization or ghunnah: (saakin /t/ followed by mutafarrik/t/):

Example (1) explains how 'Idghaam Al-Mutamaathilayn or assimilation between two non-contiguous identical sounds works under OT:

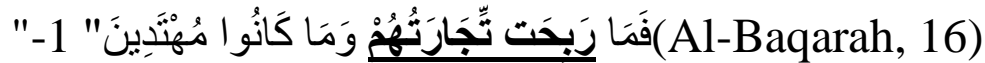

1-"They are indeed those who bartered away good guidance for error and gained nothing from the deal, nor found the right way" (Al-Awfa tran.)

In example (1), 'Idghaam Al-Mutamaathilayn takes place due to two conditions. The first condition is that the two words /ra.bi.fat.ti.Jaa.ra.tu.hum/ have two identical successive sounds. The second condition is that the first sound is saakin /-t/ and is immediately followed by mutafarrik /ti-/. Hence, the first sound /-t/ is merged into the second one $/ \mathrm{ti}-/$, and the result is a geminated sound of the second type [t ti] (Swayd, n.d; An-Nabulsi, 2008). Hence, /ra.bi.fat.ti.Zaa.ra.tu.hum/

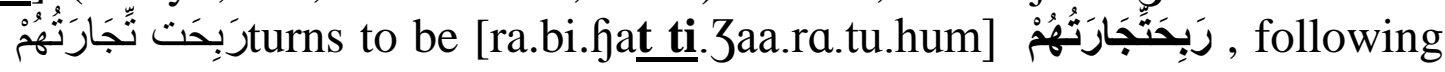
An-Nabulsi (2008). 
Table (1)

\begin{tabular}{|l|c|c|c|c|}
\hline $\begin{array}{l}\text { Input:/ra.bi.fat. } \\
\text { ti.Jaa.ra.tu.hum/ }\end{array}$ & $\begin{array}{c}\text { OCP- } \\
\text { total }\end{array}$ & $\begin{array}{c}\text { Share } \\
\text { f (M) }\end{array}$ & $\begin{array}{r}\text { Onset- } \\
\text { position } \\
\text { (M) }\end{array}$ & $\begin{array}{c}\text { Ident-IO } \\
\text { (F) }\end{array}$ \\
\hline $\begin{array}{l}\text { tro a.[ra.bi.fat } \\
\text { ti.3aa.ra.tu.hum] }\end{array}$ & & & & $*$ \\
\hline b.[ra.bi.fat.ti.3aa.ra.tu.hum] & $* !$ & $* !$ & $* !$ & \\
\hline
\end{tabular}

Table (1) shows that candidate (a) [ra.bi.fat ti.Jaa.ra.tu.hum] is the optimal and the real pronounced one. It proves that 'Idghaam AlMutamaathilayn follows OCP-total, in which the two identical sounds /-t/ and /ti-/ are prohibited. Since /t/ in / hat/ assimilates into the following /t/ in /ti/, Share $\mathrm{f}(\mathrm{M})$ is triggered. In addition, Onset-position (M) is obeyed as the second mutafarrik /ti/ in onset position (strong) dominates the first saakin /t/ in coda position (weak). However, Ident-IO (F) is violated, because the input form /ra.bi.fat.ti.Jaa.ra.tu.hum/ is not identical to the output form [ra.bi.fat ti.3aa.ra.tu.hum]. The unassimilated output candidate (b) [ra.bi.fat. ti.Zaa.ra.tu.hum] is not well-formed, due to its heaviness in pronunciation, and it does not follow Arabic phonological system or rules. As a result, 'Idghaam is preferred to 'IZhaar.

Therefore, it is concluded that OCP-total outranks both Share $\mathrm{f}(\mathrm{M})$ and Onset-position (M), and Share $\mathrm{f}(\mathrm{M})$ and Onset-position (M) dominate Ident-IO (F). In other words, the ranking of these constraints is as follows: OCP-total > Share f (M), Onset-position (M) >Ident-IO (F). The same ranking of 'Idghaam Al-Mutamaathilayn is for the most part applied to the following examples: /'idaa talaSat tazaawaru/ becomes ['idaa talaSat tazaawaru] (Al-kahf, 17) and /wa qad daxaluu/ turns into [wa qad da.xa.luu] (Al-Maa'idah, 61). 
3.3.2. Assimilation of two identical sounds or 'Idghaam AlMutamaathilayn between two words with nasalization or ghunnah: (saakin $/ \mathrm{m} /$ followed by mutaharrik $/ \mathrm{m} /$ )

Example (2) presents 'Idghaam Al-Mutamaathilayn or assimilation with ghunnah or nasalization; it concerns complete assimilation of the sonorant sound $/ \mathrm{m} /$.

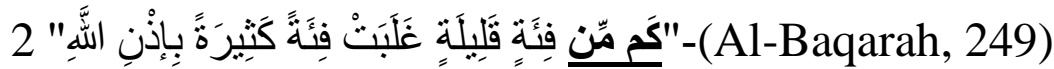

2-"Many a time has a small band defeated a large horde by the will of God. God is with those who are patient (and persevere)" (Al-Awfa tran.)

If saakin $/ \mathrm{m} /$ sound is followed immediately by mutafarrik $/ \mathrm{m} /$ within two words, the first $/ \mathrm{m} /$ will be inserted into the second $/ \mathrm{m} /$ to form one geminated sound $[\underline{\mathbf{m} \mathbf{m}}]$. Furthermore, as $/ \mathrm{m} /$ has nasalization or ghunnah as one of its characteristics, the assimilated output, the geminated sounds [m $\mathbf{m}^{\sim}$ ], is accompanied by nasalization or ghunnah for two counts (Czerepinshki \& Swayd, 2000, p.52). For this reason, this type of assimilation is called 'Idghaam bi-ghunnah or assimilation accompanied with nasalization. This type of assimilation $[\underline{\mathbf{m ~ m}}]$ occurs within two words, yet blocked within a word (Abdel-Hameed, 2009, p.174).

Example (2) examines 'Idghaam Al-Mutamaathilayn, which happens under two conditions. The first condition is that the two words /kam.min/ have two identical successive sounds. The second condition is that the first sound is saakin $/-\mathbf{m} /$ and is immediately followed by muta̧arrik /mi-/. Hence, the first sound/-m/ is merged into the second one /mi-/ and the result is a geminated sound of the second type [ $\mathbf{m} \mathbf{~ m} \mathbf{i}]$, with ghunna. Therefore, /kam.min/ turns to be [kam min] (AbdelHameed, 2009; Swayd, n.d; Abu Zayd, 2010).

Table (2)

\begin{tabular}{|l|c|c|c|c|c|}
\hline $\begin{array}{l}\text { Input: } \\
\text { /kam.m in/ }\end{array}$ & $\begin{array}{c}\text { OCP } \\
- \\
\text { total }\end{array}$ & $\begin{array}{c}\text { Share } \\
\mathbf{f} \\
(\mathbf{M})\end{array}$ & $\begin{array}{c}\text { Onset- } \\
\text { position } \\
(\mathbf{M})\end{array}$ & $\begin{array}{c}* \text { Son.Ge } \\
\mathbf{m}(\mathbf{M})\end{array}$ & $\begin{array}{c}\text { Ident-IO } \\
(\mathbf{F})\end{array}$ \\
\hline $\begin{array}{c}\text { a. [kam } \\
\text { m in] }\end{array}$ & & & & $*$ & $*$ \\
\hline b.[kam.m in] & $* !$ & $* !$ & $* !$ & & \\
\hline
\end{tabular}


Table (2) shows that the assimilated form candidate (a) [kam m in] كَّ is the optimal real pronounced output. In candidate (a) [ka $\underline{\underline{\mathbf{m}} \mathbf{m} \mathbf{i n}}$ ], the adjacency of two identical sounds between word boundaries is blocked, thus, OCP-total is triggered. Then, $/ \mathrm{m} / \mathrm{in} / \mathrm{kam} /$ assimilates into the following $/ \mathrm{m} /$ in $/ \mathrm{mi} /$. Hence, Share $\mathrm{f}(\mathrm{M})$ is activated. Moreover, it obeys Onset-position (M), as the coda (weak) $/ \mathrm{m} /$ assimilates into the onset (strong) $/ \mathrm{mi} /$. Conversely, candidate (a) violates $*$ Son.Gem (M) as it has doubled sonorants $[\underline{\mathbf{m}} \mathbf{m} \mathbf{i}]$. As a result, it violates Ident-IO (F), because the output form [ $[\mathrm{kam} \mathrm{m}$ in] is not identical to the input form $/ \mathrm{kam} . \mathrm{m}^{\mathrm{in}} /$. As for candidate (b) [kam.min], it is not an acceptable form, because of the difficulty of pronouncing the same sound twice from the same place of articulation. Consequently, OCP-total outranks Share f (M) and Onset-position (M). Next, Share f (M) and Onset-position (M) are ranked over *Son.Gem $(\mathrm{M})$, then *Son.Gem $(\mathrm{M})$ dominates Ident-IO (F). In other words, the ranking of these constraints is: OCP-total > Share $\mathrm{f}$ $(\mathrm{M})$, Onset-position $(\mathrm{M})>*$ Son.Gem $(\mathrm{M})>$ Ident-IO (F).

It is to be noted that Max-nasal (F) is not added to the table as the nasalization in both (a) [kam m in] and (b) [kam.m in] is intrinsic to them. They have nasalization as a feature of the $/ \mathrm{m} /$ sound; and not as a new feature added to them, as explicated by Abu Zayd (2010, p.84).

The previous ranking of constraints is also applicable to the following phrases: [xa.la.qa la.kum ma a fi 1-'ardi] (Al-Baqarah, 29) and ['am mªn. 'as.sa.sa] (At-Tawbah, 109).

\subsubsection{Exceptions for' 'Idghaam Al-Mutamaathilayn}

\section{(a) 'Idghaam Al-Mutamaathilayn between two mutafarrik identical sounds within one word with nasalization or ghunnah: (mutafarrik /n/ followed by another mutafarrik /n/)}

In recitations other than Hafs, assimilation takes place between two identical mutafarrik sounds. However, according to Hafs, when two identical mutafarrik sounds come after each other, assimilation is blocked, and 'IZhaar is applied instead; except for few words (AbdelHameed, 2009, pp.157-158). In these exceptional few words, Sibawayh (n.d.) illustrates that when two identical consonant sounds are separated by a short vowel, 'Idghaam takes place in two levels: first, the short vowel between the two consonants is deleted. Next assimilation is applied when the two successive identical sounds are a saakin sound followed by a mutafarrik (as cited in An-Nasser, 1985, p.108). The following word examplifies an exception in Hafs' recitation, in which 'Idghaam Al- 
Mutamaathilayn or assimilation between two mutafarrik sounds in one word is applied, where 'Idghaam is stronger than 'IZhaar in this example:

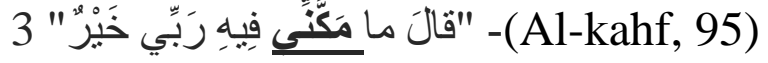

3- "He said, "That in which my Lord has established me is better [than what you offer] ..." (KSU. tran.)

In example (3), the underlying form /mak.ka.na.nii/ has two successive mutafarrik nasal sounds, which leads to heaviness in pronunciation. Therefore, Arabs, in these words, tend to change the first sound into saakin by deleting the following short vowel /a/; thus, /mak.ka.na.nii/ turns to be [mak kan n ii]. The assimilation process takes place as usual in which the first sound /-n/ is merged into the second one /nii-/, and the result is a geminated sound of the second type [n ñ ] (Swayd, n.d; AbdelHameed, 2009). In addition, the geminated form [n $\left.\mathbf{n}^{\sim}\right]$ has nasalization for two counts out of the nasality of /n/ (Abu Zayd, 2010, p.84).

Table (3)

\begin{tabular}{|c|c|c|c|c|c|c|}
\hline $\begin{array}{l}\text { Input: } \\
\text { /mak.ka.na.nii/ }\end{array}$ & OCP-total & $\begin{array}{l}\text { Share f } \\
\text { (M) }\end{array}$ & $\begin{array}{c}\text { Onset- } \\
\text { position }(M)\end{array}$ & $\begin{array}{l}\text { *Son.Gem } \\
\text { (M) }\end{array}$ & $\begin{array}{l}\text { Max-IO } \\
\text { (F) }\end{array}$ & $\begin{array}{l}\text { Ident-IC } \\
(\mathrm{F})\end{array}$ \\
\hline a.[mak kan ñii $]$ & & & & $*$ & $*$ & $*$ \\
\hline b.[mak.ka.na.nii] & $* !$ & $* !$ & $* !$ & & & \\
\hline
\end{tabular}

Table (3) explains that candidate (a) [mak kan n nii] كَكَنَّنِ is the optimal output form, yet, candidate (b) [mak.ka.na.nii] is not allowed. The optimal output form (a) obeys OCP-total as a result of the deletion of the vowel to prevent the adjacency of two successive identical sounds $/ \mathrm{n} /$ and /nii/. Then the first $/ \mathrm{n} /$ assimilates into the second /nii/. Consequently, Share $\mathrm{f}(\mathrm{M})$ is also obeyed. Furthermore, it obeys Onset-position (M) as the the stronger second /nii/ in the onset position dominates the weaker first one $/ \mathrm{n} /$ in the coda position. However, *Son.Gem (M) is violated, because by applying OCP-total, Share $\mathrm{f}(\mathrm{M})$ and Onset-position (M), a geminated form of sonorant [ $\left.\underline{\mathbf{n} \mathbf{n}^{\sim}}\right]$ is generated. Moreover, Max-IO (F) is violated as the short vowel in the input form /mak.ka.na.nii/ does not have a correspondant in the output form [mak kan n ii] , and it is dropped. Ident-IO (F) is also violated in which the input form is not identical to the output form, i.e. it loses the short vowel between the two $/ \mathrm{n} /$ sounds, in addition to the appearance of the geminated form [ $\underline{\mathbf{n}} \mathbf{n} \tilde{]}]$. Both *Son.Gem (M) and Max-IO (F) are on the same level, as there is no priority of applying one over another. Furthermore, *Son.Gem (M) and Max-IO (F) are ranked higher than Ident-IO, in correspondence with Al-Hashimi's 
analyses (2004). Accordingly, the ranking of these constraints is as follow: OCP-total> Share f (M), Onset-position (M) > *Son.Gem (M), Max-IO (F) > Ident-IO (F). The same ranking of constraints is applied to [ta'.mu.ruun n nii] (Az-Zumar, 64) and ['a.tu.faaz.zuun ñii] (Al'anSaam, 80).

(b) Blocking of 'Idghaam Al-Mutamaathilayn between a long vowel immediately followed by its semi-vowel counterpart://uu/ or /ii/ followed by $/ \mathrm{w} /$ or $/ \mathrm{y} /$ ) between two words

Ancient and Modern Arab linguists consider the sequence of /uu/ or /ii/ followed by /w/ or /y/ respectively as an exception to 'Idghaam AlMutamaathilayn. Sibawayh (n.d.) demonstrates that 'Idghaam is not applied when /uu/ or /ii/ precedes /w/ or /y/. He affirms that "[a] semivowel too cannot be involved in 'Idghaam with a pure long vowel". Thus, he illustrates that 'IZhaar is better than 'Idghaam under this condition. He further states that 'Idghaam is blocked in this case, whether these sounds occur within a word or across word boundaries (as cited in An-Nasser, 1985, pp.110-112). In addition, other Arab linguists as Ibn Ginni (n.d.) consider long vowels and their semi-vowel counterparts as Mutamaathilayn except in duration (as cited in Alfozan, 1989, pp.27-28). Likewise, the two tajweed scholars Al-Jamzuuriy (n.d.) and Al-Jazariy (798 Ah) classify these sounds as Mutamaathilayn. Hence, Al-Jamzuuriy in the following lines categorizes the blocking of 'Idghaam between /uu/ or $/ \mathrm{ii} /$ and $/ \mathrm{w} /$ or $/ \mathrm{y} /$ under 'Idghaam Al-Mutamaathilayn. He sums up such blocking of 'Idghaam as follows:

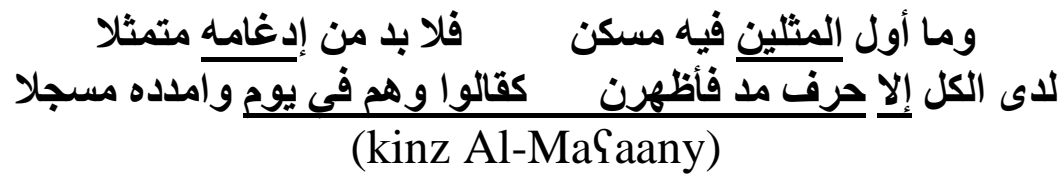

The following example clarifies the blocking of assimilation between a long vowel and its semi-vowel counterpart:

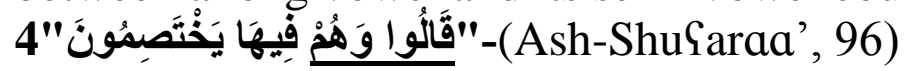

4- "Disputing among themselves they will say" (Al-Awfa tran.)

Example (4) demonstrates the blocking of 'Idghaam Al-Mutamaathilayn between the long vowel /-uu/ followed by its counterpart semi vowel /w-/ in /qaaluu wa hum/ (Abdel-Hameed, 2009; An-Nabulsi, 2008). Swayd (n.d) justifies this by saying that Arabs prefer to keep long vowels (n.p.). 


\begin{tabular}{|l|c|c|c|c|c|}
\hline \multicolumn{1}{|c|}{ /qaa.luu.wa.hum/ } & $\begin{array}{l}\text { IO } \\
\text { (F) }\end{array}$ & $\mathbf{m}$ (M) & $\begin{array}{c}\text { [+labial } \\
\text { ] }\end{array}$ & $\begin{array}{c}\text { mi- } \\
\text { vowel } \\
(\mathbf{M})\end{array}$ & (M) \\
\hline $\begin{array}{l}\text { a. } \\
\text { a.qaa.luu.wa.hum] }\end{array}$ & & $*$ & $*$ & $*$ \\
\hline $\begin{array}{l}\text { b.[qaa.1 } \underline{\mathbf{w} \text { wa }} \\
\text { hum] }\end{array}$ & $* !$ & $* !$ & & & \\
\hline
\end{tabular}

Table (4)

Table (4) supports that the unassimilated form candidate (a) [qaa.luu.wa hum] قَالَُوا وَهُهُ in the optimal output form in which 'Idghaam

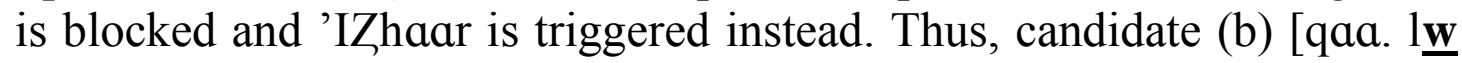
wa hum], in which assimilation takes place, is not preferred in CA. Furthermore, the above table proves that the optimal candidate (a) [qaa.luu.wa hum] obeys Ident-IO (F) in which the input form is identical to the optimal output form. Furthermore, it obeys *Son.Gem (M) as it avoids the gemination of two sonorants: /w/ and /uu/. However, it violates OCP-[+labial], as /uu/ (bilabial vowel) and /wa/ (bilabial glide) share the same place feature; both of which are [+labial]. Additionally, candidate (a) violates the complex: *VV.Semivowel (M), because the sequence of a long vowel and its semi-vowel counterpart is not allowed.

Moreover, it deactivates Share $\mathrm{f}(\mathrm{M})$ as /uu/ is followed by /wa/ in the optimal candidate (a) without sharing features from each other. Consequently, Ident-IO (F) outranks *Son.Gem (M), then *Son.Gem (M) dominates and is ranked over both OCP-[+labial] and *VV.Semi-vowel (M). Lastly, OCP-[+labial] and *VV.Semi-vowel (M) outrank Share f (M), i.e. Ident-IO (F) >*Son.Gem (M) > OCP-[+labial], *VV.Semi-vowel $(\mathrm{M})>$ Share $\mathrm{f}(\mathrm{M})$. The above proven ranking of constraints is also applied to ['aa.ma.nuu.wa Samiluu as saalifati] (Al-Baqarah, 82) and [qaaluu wa 'aqbalu Salayhim] (Yusuf, 71), in which 'IZhaar is prefered to 'Idghaam.

\subsubsection{List of constraints as regards 'Idghaam Al-Mutamaathilayn}

In sum, the previous analyses find that 'Idghaam AlMutamaathilayn in the cited examples of LHQ is mainly based on the following rankings:

(a) OCP-total > Share f (M), Onset-position (M) > Ident-IO (F).

(b) OCP-total > Share f (M), Onset-position (M) >*Son.Gem (M)> Ident-IO (F). 
(c) OCP-total > Share f (M), Onset-position (M) > *Son.Gem (M), MaxIO $(\mathrm{F})>$ Ident-IO (F).

The above rankings prove that (c) includes both (a) and (b). Thus, it is concluded that 'Idghaam Al-Mutamaathilayn is based on the following ranking of constraints:

(1) OCP-total > Share f (M), Onset-position (M) > *Son.Gem (M), MaxIO $(\mathrm{F})>$ Ident-IO (F).

It is deduced from (1) that the ranking for 'Idghaam Al-Mutamaathilayn is that OCP-total occupies the highest rank and outranks other constraints. It is ranked over Share $f(M)$ and Onset-position (M). Then, Share $f(M)$ and Onset-position (M) dominate *Son.Gem (M) and Max-IO (F). Finally, Ident-IO (F) is in the lowest rank.

However, the blocking of 'Idghaam Al-Mutamaathilayn in the chosen instances of LHQ is based on the following rankings:

(a) Ident-IO (F) $>*$ Son.Gem (M) > OCP-[+labial], *VV.Semi-vowel (M) $>$ Share $\mathrm{f}(\mathrm{M})$.

Thus, (a) proves that Ident-IO (F) ('IZhaar) occupies the highest rank in the blocking of 'Idghaam Al-Mutamaathilayn in the example, while Share $\mathrm{f}(\mathrm{M})$ is in the lowest rank.

\subsection{Assimilation of two similar sounds or 'Idghaam Al- Mutajaanisayn}

'Idghaam Al-Mutajaanisayn is another phonological rule in the Qur'anic phonotactics that is tackled in this study. It takes place between two adjacent sounds, the first of which is saakin and the second is mutafarrik. They are two different sounds, yet, they share the same place of articulation (Abdel-Hameed, 2009, p.159). Consequentely, 'Idghaam Al-Mutajaanisayn takes place to block the existence of two adjacent similar sounds sharing the same place of articulation. Al-Jazariy (798 Ah) illustrates 'Idghaam Al-Mutajaanisayn in the following line:
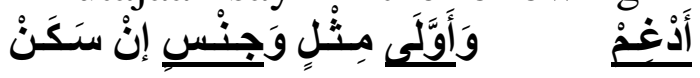

(Al-Jazariyyah 50)

Like 'Idghaam Al-Mutamaathilayn, 'Idghaam Al-Mutajaanisayn is preferred to 'IZhaar between two similar sounds with the same place of articulation. 


\subsubsection{Analysis}

\subsection{1. 'Idghaam Al-Mutajaanisayn between two similar sounds between two words: (/-t/ saakinah followed by /t-/ mutafiarrikah)}

Sibawayh (n.d.) examines the combination of /t/ (a voiceless velarized alveolar stop) and /t/ (a voiceless alveolar stop). He clarifies that when the mutafarrik /t-/ occurs second in combination with saakin /$\mathrm{t} /$, a complete assimilation takes place, producing the geminate form [t taa]. He enlists three reasons for this complete assimilation. First, he refers to the fact that $/ \mathrm{t} /$ is stronger than $/ \mathrm{t} /$; it is a velarized sound that has [+Mutbaq] "emphatic feature". He also assigns that the emphatic feature has phonological strength that affects the basic direction of assimilation, thus, $/ \mathrm{t} /$ dominates $/ \mathrm{t} /$. Second, he refers to saakin sound as "the weakest unit in the structure and describes it as a 'dead entity'". Third, he underlines "the relative positional strength" between two consonant sounds. He advocates that "a consonant in syllable initial position must be considered stronger than a consonant in syllable final position" (as cited in An-Nasser, 1985, pp.105, 128). The following example demonstrates a complete regressive assimilation of two similar sounds between word boundaries:

5 "(Aal-Yimraan, 122)

5- "When two of your bands were about to lose heart God befriended them; and in Him should the faithful place their trust"(Al-Awfa tran.).

In example (5), /ham.mat taa.'i.fa.taan/, /-t/ saakinah is completely assimilated to the following mutafarrik /taa-/. Complete assimilation takes place due to the fact that $/ t /$ is stronger than $/ t /$. Thus, /ham.mat.taa.'i.fa.taan/ هَمَّتْن طَائفَنَّانِ turns to be [ham matrtaa.'i.fa.taan] هَمَّطَائفَنَانِ (An-Nabulsi, 2008), where the English transcription is provided by the researcher.

Table (5)

\begin{tabular}{|l|c|c|c|c|c|}
\hline Input: & OCP- & Share & Onset- & Max-IO & Ident- \\
/ham.mat.taa.'i.fa.taan/ & [+coronal] & f (M) & position & (Emphatic) & IO \\
\hline
\end{tabular}




\begin{tabular}{|c|c|c|c|c|c|}
\hline & & & $(\mathbf{M})$ & & $(\mathbf{F})$ \\
\hline $\begin{array}{l}\text { a. [ham } \\
\text { matytaa.'i.fa.taan] }\end{array}$ & & & & & $*$ \\
\hline $\begin{array}{c}\text { b.[ham.mat. } \\
\text { taa.'i.fa.taan] }\end{array}$ & $* !$ & $* !$ & & & \\
\hline $\begin{array}{c}\text { c.[ham.mat } \\
\text { taa.'i.fa.taan] }\end{array}$ & & & $* !$ & $* !$ & $*$ \\
\hline
\end{tabular}

Table (5) explains that the optimal candidate is (a) [ham matytaa.'i.fa.taan], in which complete assimilation takes place. It obeys OCP-[+coronal] as it rejects the adjacency of the two coronal sounds /-t/ (voiceless alvealor stop) and /tad/ (voiceless velarized alvealor stop). Consequently, Share $\mathrm{f}(\mathrm{M})$ is obeyed in which / $\mathrm{t} / \mathrm{shares}$ the velarization of $/ \mathrm{t} /$. In addition, it obeys Onset-position (M) in which the stronger $/ \mathrm{taa} /$ in the onset position affects the preceding weaker/-t/ in the coda position. Furthermore, (a) obeys Max-IO (Emphatic) in which the emphatic feature of $/ \mathrm{t} /$ in the input form is still found in the output form. Lastly, the optimal output violates Ident-IO (F), as it is not identical to the input form. The researcher agrees with Al-Hashimi's analysis (2004) that MaxIO (Emphatic) and Ident-IO (F) are in conflict with each other, hence, Max-IO (Emphatic) is ranked over Ident-IO (F).

Therefore, both candidate (b) [ham mat.taa.'i.fa.taan], in which 'IZhaar is applied and candidate (c) [ham mat taa.'i.fa.taan], in which the stronger sound $/ \mathrm{t} /$ assimilates completely to the weaker one $/ \mathrm{t} / \mathrm{are}$ blocked. Consequently, OCP-[+coronal] is ranked over Share $\mathrm{f}(\mathrm{M})$ and Onset-position (M). Both Share f (M) and Onset-position (M) are ranked higher than Max-IO (Emphatic). Then Max-IO (Emphatic) dominates Ident-IO (F). OCP-[+coronal] > Share f (M), Onset-position (M)> MaxIO (Emphatic) > Ident-IO (F). Furthermore, this ranking of constraints is applicable to [fa.'aa.ma.natytaa.'i.fa.tun] (As-saf, 14).

\subsection{2. 'Idghaam Al-Mutajaanisayn between two similar sounds within one word:(/t/ saakinah followed by /t/ mutafarrikah)}

Sibawayh (n.d.) decrees that when / $t /$ saakinah is followed by $/ t /$ mutafarrikah, the assimilation process takes place, in which the / $t /$ assimilates to the next $/ \mathrm{t} /$. In addition, he upholds that a non-velarized segment as $/ \mathrm{t} /$ is not allowed to dominate a velarized one as $/ \mathrm{t} /$. In other words, the weaker feature of a sound must not be allowed to dominate a stronger one. Thus, the assimilated form keeps the [+Mutbaq] or 
[+Emphtic] feature of the assimilated [t] on the produced geminated form $\left[\begin{array}{ll}\mathbf{k} & \mathbf{t}\end{array}\right]$. Therefore, $/ \mathrm{t} /$ keeps its velarized feature on the output form. Thereupon, this case is of an incomplete assimilation out of velarization (as cited in An-Nasser, 1985, pp.127-128). Al-Jazariy (798 Ah) concludes in the following line that:

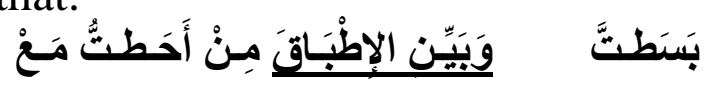

(Al-Jazariyyah 46)

Hence, incomplete assimilation is preferred to complete assimilation.

The following verse examplifies the incomplete assimilation between /t/ saakinah followed by /t/ muta̧arrik:

6 "(Al-Maa'idah, 28)"

6- "If you should raise your hand against me to kill me - I shall not raise my hand against you to kill you. Indeed, I fear Allah, Lord of the worlds" (KSU tran.).

In example (6), /t/ and /t/ share the same place of articulation, for both are alveolar [+coronal] and are directly adjacent to each other. Yet, $/ t /$ is stronger than $/ \mathrm{t} /$, as it is a velarized sound, while $/ \mathrm{t} /$ is a non-velarized sound. Thus, / $t /$ is not completely assimilated to /ta/ because of its emphatic feature, thus, it mantains its emphatic feature on the new assimilated form (Abdel-Hameed, 2009; Swayd, n.d), i.e. [t⿳‥t]

Table (6)

\begin{tabular}{|c|c|c|c|c|c|}
\hline $\begin{array}{l}\text { Input: } \\
\text { /ba.sat.ta/ }\end{array}$ & $\begin{array}{c}\text { OCP- } \\
{[+ \text { coronal }]}\end{array}$ & $\begin{array}{c}\text { Share } \\
\text { f } \\
(\mathbf{M})\end{array}$ & $\begin{array}{c}\text { Onset- } \\
\text { position } \\
\text { (M) }\end{array}$ & $\begin{array}{c}\text { Max-IO } \\
\text { (Emphatic) } \\
\text { (F) }\end{array}$ & $\begin{array}{l}\text { Ident- } \\
\text { IO } \\
\text { (F) }\end{array}$ \\
\hline a.[ba.satyta] & & & & & $*$ \\
\hline b.[ba.sat.ta] & $* !$ & $* !$ & & & \\
\hline ta] c.[ba.sat & & & & $* !$ & * \\
\hline d. [ba.sat & & & *! & $* !$ & $*$ \\
\hline
\end{tabular}


Table (6) proves that candidate (a) [ba.satytta] بَّنَ is the optimal output form in which incomplete assimilation takes place between $/ \mathrm{t} /$ saakinah followed by /ta/ mutafarrikah. It obeys OCP-[+coronal] in which $/ t /$ is not allowed to the adjacency of similar / $/$. Hence, it obeys Share $\mathrm{f}(\mathrm{M})$ as $/ \mathrm{t} /$ assimilates partially in to $/ \mathrm{t} /$ : [tyt]. In addition, Onsetposition (M) is obeyed as $/ \mathrm{t} /$ in the coda position is assimilated into $/ \mathrm{ta} / \mathrm{in}$ the onset position. Then candidate (a) obeys Max-IO (Emphatic) (F) in which the emphatic feature of the input is realized in the output. Nonetheless, it violates Ident-IO $(\mathrm{F})$ as the output form changes phonetically from its input form /ba.sat.ta/. In candidate (b), however, [ba.sat.ta], the unassimilated one is blocked. Moreover, candidate (c) [ba.sat ta], which represents complete assimilation of $/ \mathrm{t} /$ into $/ \mathrm{t} / \mathrm{is}$ also prohibited. Besides, candidate (d) [ba.sat ta] that displays complete assimilation of $/ \mathrm{t} /$ into $/ \mathrm{t} /$ is not allowed. Accordingly, OCP-[+coronal] is ranked over Share $f(M)$ and Onset-position $(M)$. Share $f(M)$ and Onsetposition (M) dominate Max-IO (Emphatic) (F). Finally, Ident-IO (F) is at the lowest rank, i.e. OCP-[+coronal] > Share $\mathrm{f}(\mathrm{M})$, Onset-position (M)> Max-IO (Emphatic) (F) > Ident-IO (F). The same ranking of the previous proven ranking of constraints is also applied to: [far.ratstum] (Yusuf, 80) and [far.ratytun] (Az-Zumar, 56).

\subsubsection{List of constraints for 'Idghaam Al-Mutajaanisayn}

To sum up, the previous analyses prove that 'Idghaam AlMutajaanisayn in the presented examples is built upon the following ranking of constraints:

(1) OCP-[+coronal] > Share f (M), Onset-position (M)> Max-IO (Emphatic) (F) >Ident-IO (F).

As a result, in 'Idghaam Al-Mutajaanisayn, OCP-[+coronal] is positioned in the highest rank followed by Share $\mathrm{f}(\mathrm{M})$ and Onset-position (M). Then they are followed by Max-IO (Emphatic) (F). Finally, Ident-IO (F) occupies the lowest rank.

3.5. Assimilation of two proximal sounds or 'Idghaam AlMutaqaaribayn 
'Idghaam Al-Mutaqaaribayn or the assimilation of two proximal sounds refers to the assimilation between two sounds, the first of which is saakin and the second is mutafarrik. These two sounds have different features and different places of articulation, but they are still close to each other (Swayd, n.d.; Read with Tajweed, n.d). In other words, it is the "assimilation of related sounds" (Elramli, 2012, p.73).

\subsubsection{Analysis}

3.5.1. 'Idghaam Al-Mutaqaaribayn between two nasals with nasalization: (/n/ saakinah followed by /m/ mutafarrikah) between two words

'Idghaam Al-Mutaqaaribayn or the assimilation of two proximal sounds concerns here the nasal sounds $/ \mathrm{n} /$ and $/ \mathrm{m} /$. It occurs when the $/ \mathrm{n} /$ of a noon saakinah $(/ \mathrm{n} /$ as a consonant) or the $/ \mathrm{n} /$ of a nunation at the end of a word are followed by a word that starts by /maa/ mutafarrikah, then $/ \mathrm{n} /$ is inserted into $/ \mathrm{m} /$ to form a geminated [mm]. In other words, the alveolar nasal /n/ turns to be bilabial nasal [m] (Alfozan, 1989, p.100). Sibawayh (n.d.) affirms that this type of assimilation between $/ \mathrm{n} / \mathrm{and} / \mathrm{m} /$ is due to the great similarity between them, and he categorizes them as a phonetically natural class. They share the same manner of articulation; (both of them are [+nasal] and [+sonorant]). Yet, he differentiates between the two nasal consonant sounds in the place of articulation, as $/ \mathrm{m} /$ is a bilabial nasal and $/ \mathrm{n} /$ is an alveolar nasal. Abu Zayd (2010) clarifies that assimilation, in this case, is accompanied by nasalization or ghunnah for two counts (p.84).

Furthermore, Sibawayh (n.d.) points out that assimilation takes place between $/ \mathrm{n} /$ followed by /maa/ only between two words, and it is prohibited within one word, in order not to change the semantic meaning of a word (as cited in An-Nasser, 1985, pp.121-122). The following example clarifies how this type of 'Idghaam Al-Mutaqaaribayn works:

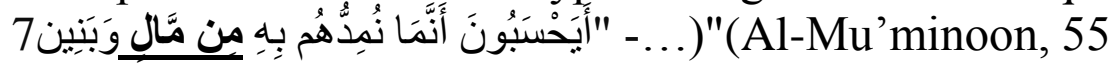

7- "Do they think that what We extend to them of wealth and children Is [because] We hasten for them good things?" (KSU trans.)

Example (7) exhibits that /-n/ saakinah in $/ \mathrm{min} /$ is assimilated to the following mutafarrik $/ \mathrm{maa} / \mathrm{in} / \mathrm{maal} /$, due to the closeness of their properties: both of them are nasals and sonorants (Abdel-Hameed, 2009; Al-Hashimi, 2004; An-Nabulsi, 2008). Therefore, /min.maa.lin/ turns to be [mim mªa.lin] مِمَّال. 


\begin{tabular}{|c|c|c|c|c|c|}
\hline $\begin{array}{l}\text { Input: } \\
\text { /min.maa.lin/ }\end{array}$ & $\begin{array}{c}\text { OCP- } \\
{[+ \text { nasal] }}\end{array}$ & $\begin{array}{c}\text { OCP- } \\
{[+ \text { sonorant }]}\end{array}$ & $\begin{array}{l}\text { Share } \\
\text { f (M) }\end{array}$ & $\begin{array}{l}\text { Onset- } \\
\text { position } \\
\text { (M) }\end{array}$ & $\begin{array}{l}\text { *Son.Gem } \\
\text { (M) }\end{array}$ \\
\hline $\begin{array}{l}\text { ma. }[\mathrm{mim} \\
\text { maa.lin] }\end{array}$ & & & & & $*$ \\
\hline b.[min.maa.lin] & $* !$ & & $* !$ & $* !$ & \\
\hline
\end{tabular}

Table (7) explains that candidate (a) [mim m aa.lin] is the optimal output form, in which complete assimilation is triggered. It obeys both OCP-[+nasal] and [+sonorant] in which the sequence of the two nasal sonorants $/ \mathrm{n} /$ saakinah followed by /maa/ mutafarrikah is not allowed. Consequentely, Share $\mathrm{f}(\mathrm{M})$ is applied to $/ \mathrm{n} / \mathrm{in} / \mathrm{min} /$ and it is assimilated to the following $/ \mathrm{m} / \mathrm{in} / \mathrm{maa} /$ to form [m maa] with nasalization. Besides, Onset-position (M) is obeyed as /maa/ in the onset position is stronger than $/ \mathrm{n} /$ in the coda position. Conversely, the optimal output [mim mªa.lin] violates *Son.Gem (M), as the gemination of two sonorants $\left[\underline{\mathbf{m ~ m}} \mathbf{m}^{\sim}\right]$ occurs. Finally, it violates Ident-IO $(\mathrm{F})$ due to the change that the output form undergoes. Moreover, candidate (b) [min.maa.lin] in which 'IZhaar is applied is prohibited. As a result, OCP-[+nasal] and [+sonorant] dominate Share $\mathrm{f}(\mathrm{M})$ and Onset-position $(\mathrm{M})$. Then Share $\mathrm{f}(\mathrm{M})$ and Onset-position (M) outrank *Son.Gem (M), and *Son.Gem $(\mathrm{M})$ is ranked higher than Ident-IO (F), i.e. OCP-[+nasal], OCP-[+sonorant] > Share $\mathrm{f}(\mathrm{M})$, Onset-position $(\mathrm{M})>*$ Son-Gem $(\mathrm{M})>$ Ident-IO (F).

\subsection{2.'Idghaam Al-Mutaqaaribayn between /l/ saakinah followed by} /r/mutafarrikah in two words

In LHQ, 'Idghaam Al-Mutaqaaribayn takes place when /1/ saakinah is followed by mutafarrik $/ \mathrm{r} /$. Al-Jazariy (798 Ah) illustrates this in the following line:

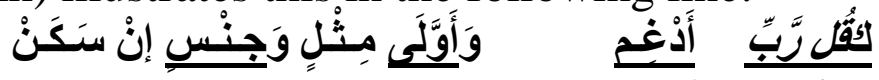

(Al-Jazariyyah 50)

Sibawayh (n.d.) also mentions this in the following line:

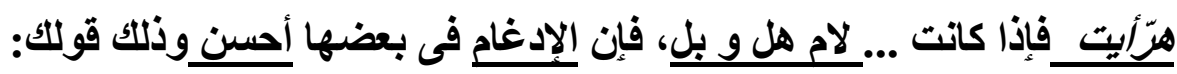

(vol.4, p.457) 
He makes a comparison between the phonetic features of $/ \mathrm{l} /$ and $/ \mathrm{r} /$ to account for the occurrence of assimilation between them. Concerning manner feature, he remarks that both sounds are [+sonorant]. /1/ is [+lateral], while $/ \mathrm{r} /$ is partially [+lateral]. He describes $/ \mathrm{r} /$ "as partially lateral", he elucidates that the tongue comes into contact with the alveolar ridge every time it taps and the airstream passes during this brief period. Moreover, both /l/ and /r/ share the same place feature; they are [+coronal]. Hence, when /l/ saakinah is followed by /r/ mutafarrikah, /l/ is completely assimilated to the following sound $/ \mathrm{r} /$ to form a complete geminated $[\underline{\mathbf{r}} \mathbf{r}]$. He justifies that "'Idghaam is 'better' and more probable in this context", due to the similarity between these two sounds (as cited in An-Nasser, 1985, pp.91, 115, 125).

The following verse exemplifies 'Idghaam Al-Mutaqaaribayn between $/ 1 /$ and $/ \mathrm{r} /$ :

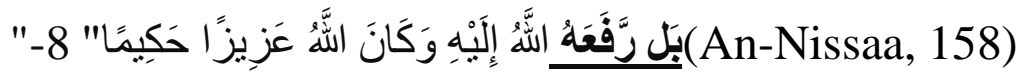

8- "But God raised him up (in position) and closer to Himself; and God is all-mighty and all-wise"(Al-Awfa tran.).

Example (8) shows 'Idghaam Al-Mutaqaaribayn in which /1/ is assimilated to the following / $\mathrm{ra} /$ to form $[\underline{\mathbf{r}} \mathbf{r}]$ due to the closeness of the two sounds: They are [+sonorant], [+lateral], and [+coronal] (AbdelHameed 2009; An-Nabulsi, 2008; Sibawayh, n.d.). Thus, /bal. ra.fa.Sa.hu/ turns to be [bar ra.fa.Sa.hu] بَرَّفَقَ

\section{Table (8)}

\begin{tabular}{|c|c|c|c|c|c|c|c|c|}
\hline $\begin{array}{l}\text { Input: } \\
\text { /bal. } \\
\text { ra.fa.Sa.hu/ }\end{array}$ & $\begin{array}{c}\text { OCP } \\
{[+ \text { corona }} \\
\text { l] }\end{array}$ & \begin{tabular}{l}
\multicolumn{1}{c}{ OCP } \\
{$[+$ sonoran } \\
t]
\end{tabular} & $\begin{array}{c}\text { OCP } \\
{[+ \text { latera }} \\
\text { l] }\end{array}$ & $\begin{array}{c}\text { *Latera } \\
\text { l. } \\
\text { Trill } \\
\text { (lr) } \\
\text { (M) }\end{array}$ & $\begin{array}{c}\text { Shar } \\
\text { ef } \\
\text { (M) }\end{array}$ & $\begin{array}{l}\text { Onset- } \\
\text { positio } \\
\text { n (M) }\end{array}$ & $\begin{array}{c}\text { *Son.Ge } \\
\text { m } \\
(\mathrm{M})\end{array}$ & $\begin{array}{l}\text { Ident- } \\
\text { IO (F) }\end{array}$ \\
\hline $\begin{array}{l}\text { a.[barra.fa.Sa.h } \\
\text { u] }\end{array}$ & & & & & & & $*$ & $*$ \\
\hline $\begin{array}{l}\text { b.[bal.ra.fa.Sa.h } \\
\text { u] }\end{array}$ & *! & *! & *! & *! & $* !$ & $* !$ & & \\
\hline
\end{tabular}

Table (8) shows that the assimilated candidate (a) [bar ra.fa.Sa.hu] is the optimal output. It obeys OCP-[+coronal], OCP[+sonorant], and OCP-[+lateral] as $/ 1 /$ and $/ \mathrm{r} /$ share close phonetic features (as mentioned above). As a result, candidate (a) obeys *Lateral.trill (M) 
in which the sequence $*[1 \mathrm{lr}]$ is avoided. As *Lateral.trill $(\mathrm{M})$ is entailed in OCP-[+coronal], [+sonorant], and [+lateral], so they are in the same stratum, following Van Goch (2010). Consequently, Share f (M) is applied as /1/ assimilates completely to the following $/ \mathrm{r} /$ and shares all its features. Onset-position (M) is also triggered as the weak /l/ in the coda position assimilates into the strong / $\mathrm{ra} /$ in the onset position. It also violates *Son.Gem $(\mathrm{M})$, because assimilation in this case leads to geminated $[\mathbf{r} \mathbf{r a}]$. Finally, Ident-IO $(\mathrm{F})$ is violated, as the optimal output (a) [bar ra.fa.Ga.hu] is not identical to the input form /bal.ra.fa.Sa.hu/. Candidate (b) [bal.ra.fa.Sa.hu], in which 'IZhaar is applied is prohibited, because of the similarity of the phonetic features between $/ 1 /$ and $/ \mathrm{r} /$. It can be concluded that OCP-[+coronal], OCP-[+sonorant], and OCP[+lateral], in addition to, $*$ Lateral.trill $(\mathrm{M})$ are ranked higher than Share $\mathrm{f}$ (M) and Onset-position (M). Then Share f (M) and Onset-position (M) outrank *Son.Gem $(\mathrm{M})$. Ident-IO $(\mathrm{F})$ is in the lowest rank, i.e. OCP[+coronal], OCP-[+sonorant], OCP-[+lateral], *lateral.trill (M)> Share $\mathrm{f}$ $(\mathrm{M})$, Onset-position (M) > *Son.Gem (M)> Ident-IO (F).

\subsection{3. 'Idghaam Al-Mutaqaaribayn between /n/ saakinah followed by one of the semi-vowels $/ y /$ or $/ w /$ between two successive words with nasalization}

Al-Jamzuuriy (1198 Ah) affirms that when a $/ \mathrm{n} /$ of a consonant or a nunation is followed by one of the two semi-vowels $/ y /$ or $/ w /$, incomplete merging happens. He explains this in the following lines of his poem:
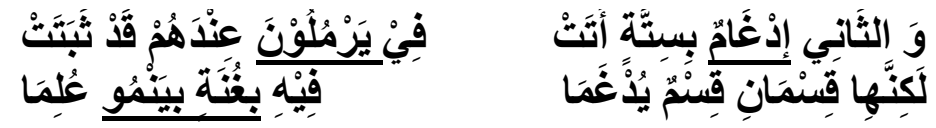

(Tuffatu-l-'ATfaal 9-10)

He displays that when /n/ saakinah is followed by one of these sounds $/ \mathrm{y} /$, $/ \mathrm{n} /, / \mathrm{m} /$, and $/ \mathrm{w} /$, assimilation with nasalization takes place. He further justifies that ghunnah is not one of the features of the two semi-vowels /y/ or $/ w /$, yet, the nasalization of the geminated form is gained from the assimilated $/ \mathrm{n} /$. In other words, the n's ghunnah is retained on the new assimilated form and the geminate outcome becomes [+nasal], [y....] or [W.....]. This is the reason for its being partial or incomplete assimilation with nasalization for two counts (Abu Zayed, 2010; Czerepinshki \& Swayd, 2000; Abdel-Hameed, 2009; Alfozan, 1989). 
The following example illustrates 'Idghaam Al-Mutaqaaribayn between $/ \mathrm{n} /$ saakinah and the semi-vowel /y/ between two successive words:

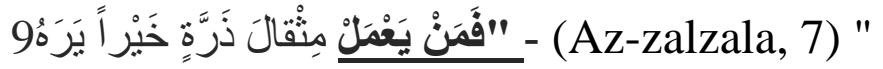

9- "Whosoever has done even an atom's weight of good will behold it." (Al-Awfa tran.)

Example (9) shows that when $/ \mathrm{n} /$ saakinah in $/ \mathrm{man} /$ is followed by the semi-vowel /y/ in /ya9mal/, /n/ assimilates to $/ \mathrm{y} /$. However, $/ \mathrm{n} /$ is not assimilated completely to $/ y /$, but it leaves its nasalization on the new assimilated form [y....] (Abdel-Hameed, 2009; Abu Zayd, 2010; Nabulsi,

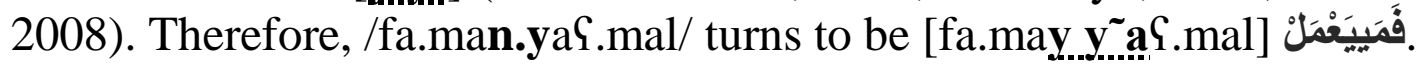

Table (9)

\begin{tabular}{|c|c|c|c|c|c|c|}
\hline $\begin{array}{l}\text { Input: } \\
\text { /fa.man.yar.mal/ }\end{array}$ & $\begin{array}{c}\text { OCP- } \\
{[+ \text { sonorant }]}\end{array}$ & $\begin{array}{l}\text { Share } \\
\text { f (M) }\end{array}$ & $\begin{array}{l}\text { Onset- } \\
\text { position } \\
\text { (M) }\end{array}$ & $\begin{array}{c}\text { Max- } \\
\text { IO } \\
\text { (Nasal) } \\
\text { (F) }\end{array}$ & $\begin{array}{l}\text { *Son.Gem } \\
\text { (M) }\end{array}$ & $\begin{array}{l}\text { Ident- } \\
\text { IO (F) }\end{array}$ \\
\hline $\begin{array}{l}\text { a.[fa.may } \\
\text { y.ạ.mal] }\end{array}$ & & & & & $*$ & $*$ \\
\hline b.[fa.man.yaS.mal] & $* !$ & $* !$ & $* !$ & & & \\
\hline $\begin{array}{l}\text { c.[fa.may } \\
\text { yaS.mal] }\end{array}$ & & $* !$ & & $*$ & $*$ & $*$ \\
\hline
\end{tabular}

Table (9) shows that candidate (a) [fa.may ya a $^{2}$ mal] is the optimal output form. It obeys OCP--[+sonorant], as the sequence of $/ \mathrm{n} /$ followed by $/ y /$ is not allowed in LHQ, due to the proximal phonetic properties between $/ \mathrm{y} /$ and $/ \mathrm{n} /$, as they are [+sonorant]. Consequently, Share $\mathrm{f}(\mathrm{M})$ is triggered as $/ \mathrm{n} /$ assimilates into $/ \mathrm{y} /$ to form a new geminated form $[\mathbf{y . \mathbf { y }}$ a] Besides, Onset-position (M) is obeyed in which /y/ in the onset position is stronger than $/ \mathrm{n} /$ in the coda position. Next, Max-IO (Nasal) (F) is activated as the new geminated form $\left[\begin{array}{ll}\mathbf{y}_{\text {....... }}\end{array}\right]$ still has nasalization. However, the resulted geminated form $\left[\begin{array}{l}\mathbf{y} . . .2 \\ \mathbf{y}\end{array}\right]$ violates ${ }^{*}$ Son.Gem $(\mathrm{M})$ which prevents sonorant gemination. Ident-IO $(\mathrm{F})$ is violated as the output form [may.......9.mal] is not identical to the input form /man.yaSmal/. Both the unasssimilated form, candidates (b) [man.ya9.mal] in which 'IZhaar is applied, and the assimilated form, candidate (c) [may ya $9 . m a l]$ in which complete assimilation takes place without nasalization are rejected. 
Therefore, the table proves that OCP-[+sonorant] is ranked over Share $\mathrm{f}(\mathrm{M})$ and Onset-position (M). Share $\mathrm{f}(\mathrm{M})$ and Onset-position (M) dominate Max-IO (Nasal) (F). Then Max-IO (Nasal) (F) outranks *Son.Gem (M), following McCarthy (2008) in that the obeyed constraint should be ranked higher than the violated one (pp.41-42). Finally, *Son.Gem (M) is ranked higher than Ident-IO (F), i.e. OCP-[+sonorant] > Share $\mathrm{f}(\mathrm{M})$, Onset-position $(\mathrm{M})>\mathrm{Max}-\mathrm{IO}(\mathrm{Nasal})(\mathrm{F})>*$ Son.Gem $(\mathrm{M})>$ Ident-IO (F).

\subsection{4. 'Idghaam Al-Mutaqaaribayn between /n/ saakinah and one of} the two lateral sounds $/ / /$ or $/ \mathrm{r} /$ between two successive words without nasalization

In LHQ, when /n/ saakinah, either of a consonant or of a nunation, is followed by $/ \mathrm{l} /$ or $/ \mathrm{r} /$ mutafarrik, $/ \mathrm{n} /$ is completely merged into $/ \mathrm{l} / \mathrm{or} / \mathrm{r} /$ to form a geminated $[\underline{\mathbf{l l}}]$ or $[\underline{\mathbf{r} \mathbf{r}}]$. In this type of assimilation, $/ \mathrm{n} / \mathrm{is}$ assimilated completely without retaining anything from its features (Abdel-Hameed, 2009; Al-Hashimi, 2004; Czerepinshki \& Swayd, 2000). Sibawayh (n.d.) mentions that this assimilation is without nasalization or ghunnah; it is a complete assimilation process. Al-Jamzuuriy (1198 Ah) highlights this point in the following line of his poem:

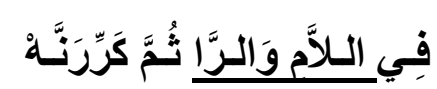

Al-Jazariy also (798 Ah) affirms that:

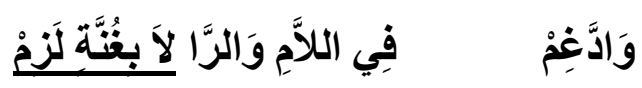

Jazariyyah 66)

Thus, both Al-Jamzuuriy and Al-Jazariy emphasize that when /1/ or /r/ mutafarrik are preceded by $/ \mathrm{n} / \mathrm{saakinah}$, assimilation takes place. Yet, the nasalization feature of $/ \mathrm{n} /$ is not realized in the pronounced form. Sibawayh (n.d.) further demonstrates that the clusters $* / \mathrm{nl} /$ and $* / \mathrm{nr} / \mathrm{do}$ not occur in the Holy Qur'an. He elaborates, "it is difficult to realize these two clusters, because of the proximity of their places of articulations". Hence, assimilation takes place between the $/ \mathrm{n} /$ and any of the $/ \mathrm{l} /$ or $/ \mathrm{r} /$ sounds; because they have adjacent places of articulation to $/ \mathrm{n} /$; they are [+coronal] and produced by the tip of the tongue (as cited in An-Nasser, 1985, p.121).

In addition, Sibawayh (n.d.) explicates that the trill 'Mukarrar' feature of / $\mathrm{r} /$ "makes it more expansive in this environment". He believes 
that "an expansive consonant cannot be dominated by a consonant that does not possess this quality" (as cited in An-Nasser, p.120). Thus, /r/ is stronger than $/ \mathrm{n} /$ and cannot be assimilated into it, because of its strength. Moreover, the liquid / $/ /$ followed by the nasal $/ \mathrm{n} /$ is not a good sequence in the language of the Holy Qur'an; since $/ 1 /$ and $/ \mathrm{n} /$ are very similar to each other (Al-Hashimi, 2004, p.65). Example (10) represents 'Idghaam Al-Mutaqaaribayn between $/ \mathrm{n} /$ saakinah followed by $/ \mathrm{r} /$ mutafarrik between two successive words:

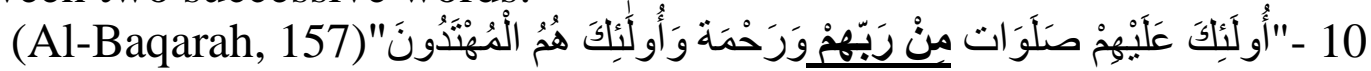
10- "On such men are the blessings of God and His mercy, for they are indeed on the right path" (Al-Awfa tran.).

Example (10) displays that when /n/ saakinah is followed by /r/ mutafarrik, /n/ is completely assimilated to the $/ \mathrm{r} /$ to form a geminated sound $[\underline{\mathbf{r}} \mathbf{r}]$. This assimilation takes place due to the closeness of the phonetic properties of $/ \mathrm{n} / \mathrm{h}$ and $/ \mathrm{r} /$; both of which are [+coronals] and [+sonorant]. Yet, $/ \mathrm{n} /$ is a [+nasal] and $/ \mathrm{r} /$ is a [+trill]. Another reason for the assimilation is that the trill feature of $/ \mathrm{r} /$ makes it stronger than $/ \mathrm{n} /$. Thus, / $\mathrm{n} /$ assimilates completely into $/ \mathrm{r}$, without nasalization (Abdel Hameed, 2009; Al-Hashimi, 2004; An-Nabulsi, 2008). As a result, /min.rab.bi.him/ turns into [mir rab bi.him] مِرَبهُهْ

\begin{tabular}{|c|c|c|c|c|c|c|c|c|}
\hline $\begin{array}{c}\text { Input: } \\
\text { /min.rab.bi.him/ }\end{array}$ & $\begin{array}{c}\text { OCP- } \\
\text { [+coronal] }\end{array}$ & $\begin{array}{c}\text { OCP- } \\
\text { [+sonorant] }\end{array}$ & $\begin{array}{c}* \text { Nas (N). } \\
\text { Lateral } \\
\text { (M) }\end{array}$ & $\begin{array}{c}\text { Share f } \\
\text { (M) }\end{array}$ & $\begin{array}{c}\text { Onset- } \\
\text { position } \\
\text { (M) }\end{array}$ & $\begin{array}{c}* \text { Son- } \\
\text { Gem } \\
(\mathbf{M})\end{array}$ & $\begin{array}{c}\text { Max- } \\
\text { nasal } \\
\text { IO(F) }\end{array}$ & $\begin{array}{c}\text { Ident- } \\
\text { IO (F) }\end{array}$ \\
\hline $\begin{array}{c}\text { (F) } \\
\text { a.[mir rab bi.him] }\end{array}$ & & & & & & $*$ & $*$ & $*$ \\
\hline b.[min.rab bi.him] & $* !$ & $* !$ & $* !$ & $*$ & $* !$ & & & \\
\hline
\end{tabular}

Table (10)

Table (10) arrays that candidate (a) [mir rab bi.him] is the optimal output and the real pronounced one. It obeys OCP-[+coronal] and OCP[+sonorant], as $/ \mathrm{n} /$ and $/ \mathrm{r} /$ have close phonetic characters; both of which are [+coronal] and [+sonorant] sounds. Moreover, it observes *Nas $(\mathrm{N})$.Lateral $(\mathrm{M})$, in which the sequence of a nasal $/ \mathrm{n} /$ followed by lateral $/ \mathrm{r} /,{ }^{*}[\mathrm{nr}]$, is banned. Accordingly, it obeys Share $\mathrm{f}(\mathrm{M})$, because $/ \mathrm{n} /$ assimilates into the following $/ \mathrm{r} /$. Onset-position (M) is activated as $/ \mathrm{ra} /$ in the onset position is stronger than $/ \mathrm{n} /$ in the coda position and assimilation takes place. As a result, candidate (a) violates $*$ Son-Gem (M), as a 
geminated form of sonorant sounds occurs $[\underline{\mathbf{r} \mathbf{r a}}]$, in addition, Max-IO (Nasal) (F) is not obeyed, because the optimal output loses the nasalization of the input form.

Furthermore, both *Son-Gem (M) and Max-IO (Nasal) (F), in this example, are not in conflict with each other, thus, they are at the same stratum in line with Al-Hashimi (2004). Finally, candidate (a) does not obey Ident-IO (F) as the output form differs from the input form. Conversely, candidates (b) [min.rab.bi.him] ('IZhaar) is blocked. Therfore, it is observed that OCP-[+coronal], OCP- [+sonorant] and *Nas.Lateral (M) dominate Share $\mathrm{f}(\mathrm{M})$ and Onset-position (M). Then Share $\mathrm{f}(\mathrm{M})$ and Onset-position $(\mathrm{M})$ are ranked over both $*$ Son-Gem $(\mathrm{M})$ and Max-IO (Nasal) (F). Ident-IO (F) comes at the lowest rank, i.e. OCP[+coronal], OCP- [+sonorant], *Nas (N).Lateral (M) > Share $\mathrm{f}(\mathrm{M})$, Onset-position (M) > *Son-Gem (M), Max-IO (Nasal) (F)> Ident-IO (F).

\subsection{5. 'Idghaam Al-Mutaqaaribayn between /q/ saakinah followed by mutafarrik $/ \mathrm{k} /$ within one word}

In LHQ, when /q/ saakinah is followed by / $\mathrm{k} /$ mutafarrikah within one word; 'Idghaam Al-Mutaqaaribayn is applied. Yet, quraa' differ whether to do complete assimilation or incomplete assimilation. AlJazariy (798 Ah) highlights this contradiction in the following line of his poem:

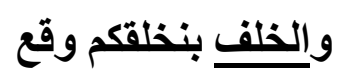

(Al-Jazariyyah 46)

Both reciters Abu Bakr Ibn Mihraan and Makkiy Ibn Abi Taalib Alqaysiy prefer incomplete assimilation between /q/ saakinah and $/ \mathrm{k} /$ mutafarrikah, in which the velarization of /q/ is kept in the output assimilated form [q $\mathrm{q}$ k] (Swayd, n.d.). Nonetheless, according to Hafs' recitation, complete assimilation is applied in which the first /q/ saakinah is assimilated completely into the second $/ \mathrm{k} /$ mutafarrikah to form the geminated sound $[\underline{\mathbf{k}} \mathbf{k}]$. Yet, it may be read as incomplete assimilation in other recitations in which /q/ leaves its emphatic feature on the $/ \mathrm{k} /$. It is the only case of a velarized sound blended into an unvelarized sound, which can be read either ways in the Holy Qur'an (Read with Tajweed Rules, n.d.; Abdel-Hameed, 2009). As a result, according to Hafs' recitation, complete assimilation is preferred to incomplete assimilation. Al-'Imaam Ahmed At-tayibi (n.d.) points out that: 


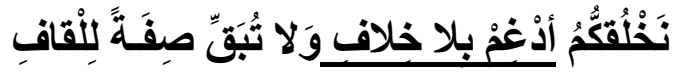

Multaqa Ahl At-tafsiir, 2013)

(As cited in

The assimilation between /q/ saakinah followed by mutafarrik / $/ \mathrm{k}$ is due to the closeness of their phonetic features. Both $/ \mathrm{k} /$ and $/ \mathrm{q} /$ have the same articulatory feature; both are [+dorsal]: /k/ is velar, while /q/ is uvular, and both are produced by the body of the tongue (Abdel Hameed, 2009; Alfozan, 1989; An-Nabulsi, 2008; Ladefoged, 1996).The following example illustrates how /q/ saakinah is assimilated when it is followed by mutafarrik $/ \mathrm{k} /$, according to Hafs' recitation.

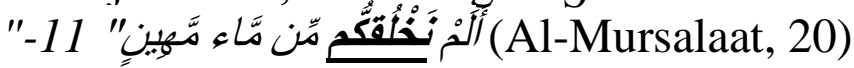

11- "Did We (refers to God) not create you from contemptible water?"

(Al-Awfa tran.)

Example (11) models that, according to Hafs' recitation, /q/ is completely assimilated to /k/ (Abdel-Hameed, 2009; An-Nabulsi, 2008; Swayd, n.d.).

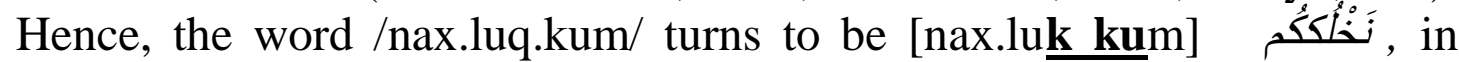
which /-q/ assimilates to the following / ku-/ to form the geminated sound [k ku] (An-Nabulsi, 2008).

Table (11)

\begin{tabular}{|l|c|c|c|c|c|}
\hline $\begin{array}{c}\text { Input: } \\
\text { /nax.luq.kum/ }\end{array}$ & $\begin{array}{c}\text { OCP- } \\
\text { [+dorsal] }\end{array}$ & $*[\mathbf{q k}$ ] & $\begin{array}{c}\text { Share } \\
\text { (M) }\end{array}$ & $\begin{array}{c}\text { Onset- } \\
\text { position } \\
\text { (M) }\end{array}$ & $\begin{array}{l}\text { Ident- } \\
\text { IO } \\
\text { (F) }\end{array}$ \\
\hline $\begin{array}{l}\text { a. [nax.luk } \\
\text { kum] }\end{array}$ & & & & & $*$ \\
\hline $\begin{array}{l}\text { b. } \\
\text { [nax.luq.kum] }\end{array}$ & $* !$ & $* !$ & $* !$ & $* !$ & \\
\hline
\end{tabular}

Table (11) displays that candidate (a) [nax.luk kum] is the optimal output form in which the sequence of $/ \mathrm{q} / \mathrm{and} / \mathrm{ku} /$ is blocked. As a result, (a) obeys OCP-[+dorsal] as /q/ and $/ \mathrm{k} /$ are dorsal consonants, following Clements' (2000) classification of sounds in respect to primary places of 
articulation (p.128). Thus, the complex $*[\mathbf{q k}](\mathrm{M})$ is triggered to block the sequence /q/ and /k/. Then, it follows Share $\mathrm{f}(\mathrm{M})$ in which /q/ is assimilated to $/ \mathrm{ku} / \mathrm{sharing}$ all its features. Additionally, Onset-position (M) is activated as $/ \mathrm{ku} /$ in the onset position is stronger than $/ \mathrm{q} / \mathrm{in}$ the coda position. As a result, the optimal output violates Ident-IO (F), because the optimal output form [nax.luk kum] is not identical to the input form [nax.luq.kum]. It can be concluded that these constraints are ranked: OCP-[+dorsal], ${ }^{*}[\mathbf{q k}](\mathrm{M})>$ Share $\mathrm{f}(\mathrm{M})$, Onset-position $(\mathrm{M})>$ Ident-IO (F).

\subsection{6. 'Idghaam Al-Mutaqaaribayn between / $/$ of the definite article} l'al-/ and "Al-huruuf ash-shamsiyyah" or "solar sounds" within a word

Another kind of 'Idghaam Al-Mutaqaaribayn or assimilation of two proximal sounds is between the / $/$ / of the definite article /'al-/ followed by one of "Al-furuuf ash-shamsiyyah" or "solar sounds" within a noun. In CA, sounds are divided into two classes: solar sounds "Alfuruuf ash-shamsiyyah" and lunar sounds "Al-ffuruuf Al-qamariyyah". There are fourteen solar sounds in CA; they are $/ \mathrm{t} /, / \mathrm{d} /, / \mathrm{z} /, / \mathrm{s} /, / \delta /, / \theta /, / Z /$, $/ \mathrm{s} /, / \mathrm{d} /, / \mathrm{r} /, / \mathrm{J} /, / \mathrm{t} /, / \mathrm{n} /$, in addition to $/ 1 /$. Arab scholars generally "include /1/ itself as one of the letters to which the /1/ of the definite article assimilates" (Alfozan, 1989, p.89). The function of the definite article /'al-/ is to make a definite noun. It is asserted that if /'al-/ is added to a noun starting with one of these fourteen sounds, /l/ of the definite article is completely assimilated to the first sound of that noun (Abdel-Hameed, 2009; Czerepinshki \& Swayd, 2000), for instance: /'al.ra.gul / turns to be ['ar ra.gul] (the man) (An-Nasser, 1985, p.124). Assimilation, in this case, is due to the proximity (taqaarub) between $/ 1 /$ and the other thirteen sounds (Abdel-Hameed, 2009, p.197), as they are pronounced from "the middle of the mouth between the dental and alveo-palatal sounds". Hence, they are articulated either in the alveolar position or in the interdental position (immediately backward in the alveo-palatal position) (Alfozan, 1989, pp.83, 85).

Sibawayh (n.d.) determines that the assimilation of /1/ of the definite article takes place due to its high frequency in speech as well as the similarity of its phonetic features with these thirteen sounds, besides the $/ 1 /$ itself. He demonstrates that $/ 1 /$ is an apical consonant and eleven out of the thirteen consonants which assimilate to $/ 1 /$ are apicals, i.e. they are produced by obstructing the air passage with the tip of the tongue. In addition, "the other two /d/ and / $/$ have places of articulation that overlap with those of the first eleven consonants". Furthermore, /l/ and the other thirteen consonant sounds are all [+coronal]. Moreover, eight of them are voiced and ten are continuant (as cited in An-Nasser, 1989, p.124). Al- 
Jamzuuriy (1198 Ah) sums up 'Idghaam Al-Mutaqaaribayn between the /1/ of the definite article /'al-/ followed by one of "Al-fjuruuf ashshamsiyyah" or "solar sounds" within a noun in the following line:

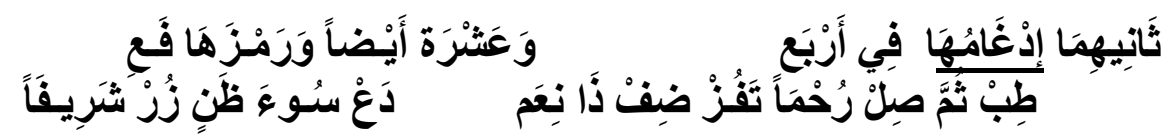

(Tuffatu-1-'ATfaal 26)

Thus, 'Idghaam is better than 'IZhaar in this case.

\subsubsection{1. / $/$ of the definite article /'al/ followed by / // in one word}

The following example reveals how assimilation of /1/ of the definite article occurs.

$$
\text { 12 "وَالثَتَّمْس وَضُحَاهَا" (Ash-Shams, 1) }
$$

12- "I CALL TO witness the sun and his early morning splendour" (AlAwfa tran.)

Example (12) reveals that in /'al.fams/, /l/ is assimilated to the following $/ \int \mathrm{a} /$ to form the geminated form [[ $\left[\mathbf{\int a}\right]$; thus, /'al.Jams/ turns to be ['a@.fams] (Abdel-Hameed, 2009, p.197). Following Sibawayh's assumption, assimilation is triggered due to the similarity between the phonetic properties of $/ 1 /$ and $/ \mathrm{g} /$. /1/ "is articulated in the alveolar position" and $/ \mathrm{J} /$ is articulated "immediately backward in the alveo-palatal position". Moreover, both /l/ and / // are [+coronal] (Alfozan, 1989, p.85).

Table (12)

\begin{tabular}{|c|c|c|c|c|c|}
\hline $\begin{array}{l}\text { Input: } \\
\text { /'al Jams/ }\end{array}$ & $\begin{array}{c}\text { OCP- } \\
\text { [+corona } \\
\text { l] }\end{array}$ & $\begin{array}{c}\text { *Latera } \\
\text { 1.Solar } \\
*[1]] \\
(\mathrm{M}) \\
\end{array}$ & $\begin{array}{l}\text { Share } \\
\text { f (M) }\end{array}$ & $\begin{array}{c}\text { Onset- } \\
\text { positio } \\
\text { n (M) }\end{array}$ & $\begin{array}{l}\text { Ident- } \\
\text { IO (F) }\end{array}$ \\
\hline a.['a〔[ams] & & & & & $*$ \\
\hline b.['al.fams] & $* !$ & $* !$ & $* !$ & $* !$ & \\
\hline
\end{tabular}


Table (12) illustrates that the optimal output candidate (a) ['a[_ams] obeys OCP-[+coronal], as both $/ 1 /$ and $/ \delta /$ are [+coronal]. In addition, it obeys *Lateral.Solar (M) which avoids the combination of $*[1]]$. Consequentely, it fulfills Share $\mathrm{f}(\mathrm{M})$ in which complete assimilation between $/ \mathrm{l} /$ and $/ \delta /$ takes place to form [ [ []]. Furthermore, Onset-position (M) is activated as $/ J /$ in the onset position is stronger than $/ 1 /$ in the coda position. However, the optimal candidate is not identical to the input form; thus, ['a〔 $[\mathrm{am}]$ violates Ident-IO (F). As a result, candidate (b) ['al.jams] is prohibited. Both OCP-[+coronal] and *Lateral.Solar (M) are ranked higher than both Share $\mathrm{f}(\mathrm{M})$ and Onset-position $(\mathrm{M})$. Share $\mathrm{f}$ (M) and Onset-position (M) outrank Ident-IO (F), i.e., OCP-[+coronal], *Lateral.Solar *[1]] (M)> Share f (M), Onset-position (M) > Ident-IO (F). Other examples on which this ranking of constraints is applied are: [as saa.li.faa.ti] (Al-Baqarah, 82) and [a[_ay.taan] (Al-Baqarah, 168).

\subsubsection{List of constraints concerning 'Idghaam Al-Mutaqaaribayn:}

This section proves that 'Idghaam Al-Mutaqaaribayn is based on the following ranking of constraints:

(a) OCP-[+nasal], OCP-[+sonorant] > Share f (M), Onset-position (M) $>*$ Son-Gem $(\mathrm{M})>\operatorname{Ident}-\mathrm{IO}(\mathrm{F})$.

(b) OCP-[+coronal], OCP-[+sonorant], OCP-[+lateral], *lateral.trill> Share $\mathrm{f}(\mathrm{M})$, Onset-position $(\mathrm{M})>*$ Son.Gem $(\mathrm{M})>$ Ident-IO (F).

(c) OCP-[+sonorant] > Share f $(\mathrm{M})$, Onset-position $(\mathrm{M})>\mathrm{Max}-\mathrm{IO}$ (Nasal) $(\mathrm{F})>*$ Son.Gem $(\mathrm{M})>$ Ident-IO (F).

(d) OCP-[+coronal], OCP-[+sonorant], *Nas (N).Lateral (M) > Share $\mathrm{f}$ $(\mathrm{M})$, Onset-position $(\mathrm{M})>*$ Son-Gem $(\mathrm{M})$, Max-IO (Nasal) $(\mathrm{F})>$ Ident-IO (F).

(e) OCP-[+dorsal], *[qk] (M) > Share f (M), Onset-position (M) > Ident-IO (F).

(f) OCP-[+coronal], *Lateral.Solar *[1]] (M)> Share f (M), Onsetposition $(\mathrm{M})>\operatorname{Ident}-\mathrm{IO}(\mathrm{F})$.

From (a) (b) (c), (d), (e) and (f), it is deduced that OCP-manner, e.g. OCP-[+nasal], OCP-[+sonorant], and OCP-[+lateral], in addition to, OCP-place, as: OCP-[+coronal] and OCP-[+dorsal] occupy the highest rank, while Ident-IO (F) comes at the lowerest rank.

\section{6. "Al-'Ikhfaa", "Hiding", or "Concealment" in LHQ}


The literal meaning of the term 'Ikhfaa' is "concealing" or "hiding". It is one of the phonological phenomena "in which both sounds are affected by one another" (Alfozan, 1989, p.67). Arab phoneticians define 'Ikhfaa' as 'the pronunciation of a non-voweled letter stripped of any shaddah, characterized between 'IZhaar and 'Idghaam with a ghunnah remaining" (Czerepinshki \& Swayd, 2000, p.46). Al-Jamzuuriy (1198) adds that 'Ikhfaa' or concealing is a state between 'IZhaar and 'Idghaam. This articulation is made without stress and with nasalization (as cited by Abu Zayd, 2010, p.89). According to Gouda (1988), 'Ikhfaa', in the science of Tajweed, is made when "the tongue does not quite touch the alveolar ridge, and the vocal cavity holding the shape of the preceding vowel and the total sound [sic] articulated through the nasal cavity". Thus, under 'Ikhfaa' 'the duration of the nasal stop shortens (timing becomes short), the following consonant becomes pre-nasalized" (as cited in Al-Hashimi, 2004, p.38). The phonological process of 'Ikhfaa' occurs in the Holy Qur'an in the following two cases:

(a) $/ \mathrm{n} /$ sakinah followed by one of these fifteen sounds: $/ \mathrm{t}, \theta, 3, \mathrm{~d}, \delta, \mathrm{z}, \mathrm{s}, \mathrm{f}$, $\mathrm{s}, \mathrm{d}, \mathrm{t}, \mathrm{Z}, \mathrm{f}, \mathrm{q}, \mathrm{k} /$, and

(b) $/ \mathrm{m} /$ sakinah followed by /b/ sound (Abdel Hameed, 2009, pp. 182, 188).

\subsubsection{Analysis}

3.6.1./n/ sakinah followed by one of these fifteen sounds: $/ t, \theta, 3, d, \delta$, $\underline{\mathrm{z}, \mathrm{s}, \mathrm{f}, \mathrm{s}, \mathrm{d}, \mathrm{f}, \mathrm{Z}, \mathrm{f}, \mathrm{q}, \mathrm{k} /}$

When $/ \mathrm{n} /$ either of a consonant or nunation is immediately followed by one of the following fifteen sounds: $/ \mathrm{t}, \theta, 3, \mathrm{~d}, \delta, \mathrm{z}, \mathrm{s}, \int, \mathrm{s}, \mathrm{d}, \mathrm{t}, \mathrm{Z}, \mathrm{f}, \mathrm{q}, \mathrm{k}$ $/, / \mathrm{n} /$ "will assimilate homorganicly and partially to these sounds". Hence, $/ \mathrm{n} /$ is "hidden" and this is called 'Ikhfaa' haqiqi, or "true 'Ikhfaa"' (AbdelHameed, 2009; Alfozan, 1989; Czerepinshki \& Swayd, 2000). AlJamzuuriy (1198 Ah) displays this in his poetry:

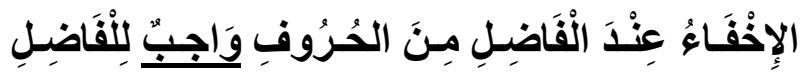

(Tuffatu-1-'ATfaal 14)

As a result, by saying "it is a must" he prefers 'Ikhfaa' to 'Idghaam and 'IZhaar. Thus, it has higher ranking.

Cohn (2014) comments that "[t]he nasal becomes more similar to the following consonant by sharing its place of articulation. Such patterns of nasal place assimilation are very common in languages" (p.89). Hence, 
in LHQ, Al-Jamzuuriy (1198 Ah) explains that the reason behind 'Ikhfaa' is the fact that the places of articulation/exits (makhaarij) of these fifteen sounds are not close enough to $/ \mathrm{n} /$ to trigger 'Idghaam and are not so far to trigger 'IZhaar. Therefore, the pronunciation of the $/ \mathrm{n} /$ before these fifteen sounds "is done in an intermediate manner" in which $/ \mathrm{n} /$ "is articulated separately from the subsequent letter, but with a slightly altered articulation" (as cited in Abu Zayed, 2010, p.90). In the process of 'Ikhfaa', the $/ \mathrm{n} /$ sound loses its place of articulation, as the tongue is no longer in its place to produce full $/ \mathrm{n} /$, but it moves toward the place of the following sound (Abdel-Hameed, 2009, p.183). Al-Jamzuuriy (1198 Ah) illustrates that: "[i]t is done without allowing the tip of the tongue to completely touch the base of the top incisors, for if the tongue were to touch them, a full nuun would be articulated. In addition, the nuun of 'Ikhfaa' is generally understood to be associated with the letter following it" (as cited in Abu Zayed, 2010, p. 90).

Sibawayh (n.d.) refers to such a $/ \mathrm{n} /$ sound as "the nasal consonant which in certain environments becomes homorganic with the consonant that immediately follows it". He calls this homorganic $[\mathrm{N}]$ as "The light Nuun" or "The concealed Nuun", and he regards light $[\mathrm{N}]$ as an allophone of $/ \mathrm{n} /$ sound or (nuun farGiyyah). Furthermore, he describes this allophone of the Nuun as "concealed sound released through the nasal cavity". $\mathrm{He}$ further explains that "the nasal property of the Nuun is sufficient to indicate its status as a phoneme and changes its place of articulation within the limits of the mouth cavity would [sic] still indicate its value as an independent segment. For this reason, he adds, a homorganic Nuun provides economy of effort" (as cited in An-Nasser, 1985, pp. 107, 123). Hence, it retains its manner of articulation or attributes and keeps the nasalization of /n/ (Abdel-Hameed, 2009, p.183).

Al-Jamzuuriy (1198 Ah) further demonstrates that 'Ikhfaa' "is done essentially as a nasalized sound (ghunnah) without overtly articulating the nuun". Thus, the light $[\mathrm{N}]$ is articulated as a ghunnah sound with its necessary duration for two counts (complete nasalization), but without overt pronunciation, and with the general attributes of the following sound. In sum, light [N], which is produced from 'Ikhfaa' of $/ \mathrm{n} /$ saakinah or tanween, has the following features: (a) it is pronounced between overt manefistation ('IZhaar) and complete assimilation ('Idghaam). Thus, light $[\mathrm{N}]$ is articulated from "the nasal cavity", and then the following sound is pronounced from "the mouth in the normal fashion". (b) It shares with the following sound its place of articulation (makhraj) and manner of articulation (attribute), yet, it still has the $/ \mathrm{n} /$ nasality (ghunnah) with its necessary duration for two counts. (c) Light 
[N] lacks emphasis or stress (shaddah) (as cited in Abu Zayd, 2010, pp.89-90).

3.6.2.'Ikhfaa' of /n/ saakinah followed by /s/ mutafarrikah within one word

The example below demonstrates the 'Ikhfaa' process, when $/ \mathrm{n} /$ saakinah is followed by /saa/ mutafarrikah within one word (contiguous sounds):

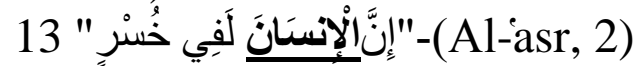

13- "Indeed, mankind is in loss ..." (KSU, tran.)

The previous example shows that when /n/ saakinah is immediately followed by /saa/ mutafarrik within one word, $/ \mathrm{n} /$ is hidden into /saa/ to form light $[\mathrm{N}]$. Sibawayh (n.d.) justifies that $/ \mathrm{n} /$ moves toward the place of articulation of the following /saa/ to make it easier in pronunciation (Abdel-Hameed, An-Nabulsi, 2008; Czerepinshki \& Swayd 2000). Therefore, /'al.'in.saan/ turns into ['al.'iN '.saan] الإِنسَّان .The following table analyzes the 'Ikhfaa' process of $/ \mathrm{n} /$ saakinah followed by /saa/ muta̧arrikah:

Table (13)

\begin{tabular}{|l|c|c|c|}
\hline $\begin{array}{l}\text { Input: } \\
\text { /'al.'in.saan/ }\end{array}$ & $\begin{array}{c}\text { OCP- } \\
\text { [+corona } \\
\text { I] }\end{array}$ & $\begin{array}{c}\text { Max-IO } \\
\text { (Nasal) } \\
\text { (F) }\end{array}$ & $\begin{array}{c}\text { Ident- } \\
\text { IO } \\
\text { (F) }\end{array}$ \\
\hline $\begin{array}{c}\text { [a. } \\
\text { ['al.'iN'.saan] }\end{array}$ & & $*$ \\
\hline $\begin{array}{c}\text { b. } \\
\text { ['al.'in.saan] }\end{array}$ & $* !$ & & \\
\hline $\begin{array}{c}\text { c. ['al.'is } \\
\text { saan] }\end{array}$ & & $* !$ & $*$ \\
\hline
\end{tabular}

In

table

(13), candidate (a) ['al-'iN .saan] is the optimal output and the real pronounced one in which $/ \mathrm{n} /$ is hidden into /saa/ to form [ $\mathbf{N}^{\sim}$.saa]. Hence, it obeys OCP-[+coronal] as /n/ and /s/ have close phonetic features; both are [+coronal]. It also observes Max-IO (Nasal) (F) as the optimal output form retains the nasalization of the input, as a result, it violates Ident-IO (F), as $/ \mathrm{n} /$ turns into its allophone [N] and the input form/'al.'in.saan/ is not identical with the output form ['al.'iN'.saan]. Both candidates (b) ['al-'in.saan] ('IZhaar), and candidate (c) ['al-'is saan] ('Idghaam) are 
prohibited. The ranking of the constraints upon which 'Ikhfaa' between $/ \mathrm{n} /$ saakinah and /saa/ mutafarrikah takes place is OCP-[+coronal] > MaxIO (Nasal) (F)> Ident-IO (F). This result is in line with Al-Hashimi's analysis, where Max-IO (Nasal) (F) is ranked higher than Ident-IO (F). Extra examples on which this ranking of constraints is applied are: [' $\mathbf{u} \mathbf{N}^{\sim}$. Z,ur] (An-Nisaa', 50), [kuN .tum] (Al-Baqarah, 23), and ['aN.zal.naa.hu] (Yusuf, 2).

\subsection{3. 'Ikhfaa' of /m/ saakinah followed by /b/ mutafiarrikah between two words}

Another case in which 'Ikhfaa' takes place concerns $/ \mathrm{m} /$ saakinah followed by /b/ mutafarrikah. Al- Al-Jazariy (798Ah) and Jamzuriy (1198 Ah) expound that if a $/ \mathrm{m} /$ saakinah is immediately followed by $/ \mathrm{b} /$ mutafarrikah between words, the $/ \mathrm{m} /$ is hidden into $/ \mathrm{b} /$ and it turns into [M .b]. The new form [M .b] is produced with ghunnah or nasalization. This type of hiding is called "'Ikhfaa' shafawy" (bilabial), because it is articulated from the two lips (as cited in Abdel Hameed, 2009, p.188). Furthermore, Al-Jazariy (798 Ah) annotates the 'Ikhfaa' of $/ \mathrm{m} /$ saakinah followed by /b/ mutafarrikah in the following lines of his poem:
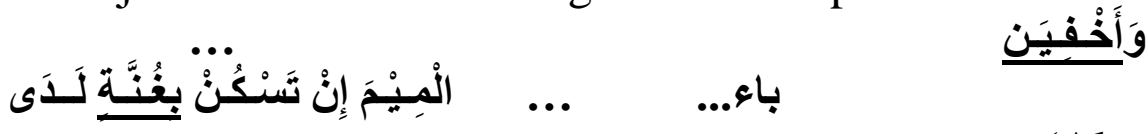

Jazariyyah 62-63)

(Al-

He explains that according to Hafs, under this condition, Al-'Ikhfaa' is preferred to Al-'IZhaar.

Sibawayh (n.d.) verifies that both $/ \mathrm{m} /$ and $/ \mathrm{b} /$ are [+labilal] sounds, in other words, their place of articulation is the lips, but the difference between $/ \mathrm{m} /$ and $/ \mathrm{b} /$ is that $/ \mathrm{m} /$ is [+ nasal] and $/ \mathrm{b} /$ is [- nasal]. He justifies that the occurrence of hiding is due to the nasality of $/ \mathrm{m} /$. The [+ nasal] feature blocks assimilation to take place and triggers 'Ikhfaa' instead (as cited in An-Nasser, 1985, pp. 113-114). The following example clarifies how 'Ikhfaa' is explained:

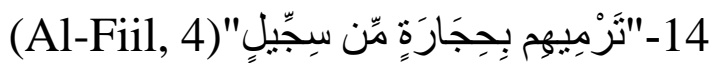
14- "(While) they were pelting them with stones of porphyritic lava," (AlAwfa tran.)

An-Nabulsi (2008) demonstrates that /tar.mii.him.bi.fi.Jaa.ra.tin/ turns to be [tar.mii.hiMr.bi.fi.Zaa.ra.tin]. As the sequence of the two sounds $/ \mathrm{m} /$ and $/ \mathrm{b} /$ is not allowed in LHQ, 'Ikhfaa' is applied in which $/ \mathrm{m} /$ will turn into its allophone $\left[\mathrm{M}^{\sim}\right]$. He justifies that assimilation is not 
applied between $/ \mathrm{m} /$ and $/ \mathrm{b} /$, in spite of the fact that both share the same place of articulation. This is due to the nasality of $/ \mathrm{m} /$, which prevents assimilation from taking place. Moreover, 'IZhaar is also blocked, because it leads to heaviness in pronunciation. Thus, 'Ikhfaa' is preferred to 'Idghaam and 'IZhaar in this case.

Table (14)

\begin{tabular}{|c|c|c|c|}
\hline$/$ Input: & $\begin{array}{c}\text { OCP- } \\
\text { [+labial] }\end{array}$ & $\begin{array}{c}\text { Max-IO } \\
\text { (Nasal) } \\
\text { (F) }\end{array}$ & $\begin{array}{c}\text { Ident-IO } \\
\text { (F) }\end{array}$ \\
\hline $\begin{array}{c}\text { a.[tar.mii.him.'Mr.bi.fji.Jaa.ra.tin } \\
\text { b.[tar.mii.him. bi.ffi.Jaa.ra.tin] }\end{array}$ & $*$ & & $*$ \\
\hline c.[tar.mii.hib bi.fi..Jaa.ra.tin] & & $* !$ & $*$ \\
\hline
\end{tabular}

Table (14) exhibits that candidate (a) [tar.mii.hiMr.bi.fi.Zaa.ra.tin] is the optimal output form and the real pronounced one, in which $/ \mathrm{m} /$ saakinah is hidden to the next $/ \mathrm{b} /$ mutafarrikah to form [ $\left.\mathrm{M}^{\sim} . \mathrm{b}\right]$ across word boundaries. Thus, it obeys OCP-[+labial] in which the two sounds $/ \mathrm{m} /$ and $/ \mathrm{b} /$ that share the same place of articulation (bilabial) are not allowed and turn to form [ $\left.\mathbf{M}^{\sim} . \mathbf{b}\right]$. Moreover, Max-IO (Nasal) (F) is obeyed as the nasalization in the input has a correspondant one in the output form. However, candidate (a) violates Ident-IO (F) as the output form is not identical to the input form. In addition, candidate (b) [tar.mii.him.bi.fi.Jaa.ra.tin] ('IZhaar), and candidate (c) [tar.mii.hib bi.ffi.Jaa.ra.tin] ('Idghaam) are prohibited. Consequently, the ranking of these constraints is: OCP-[+labial] > Max-IO (Nasal) (F)> Ident-IO (F). The same ranking is applied to [faf.kuMr.bay.na.hum] (Al-Maa'idah, 42) in which 'Ikhfaa' is prefered.

\subsubsection{List of constraints concerning 'Ikhfaa' in LHQ}

To conclude, the previous analyses prove that 'Ikhfaa' in the cases selected from LHQ is built upon the following rankings of constraints:

(a) OCP-[+coronal] > Max-IO (Nasal) (F)> Ident-IO (F), and 
(b) OCP-[+labial] > Max-IO (Nasal) (F) $>$ Ident-IO (F).

Thus, (a) and (b) prove that OCP-place [+coronal] and [+labial] are at the highest rank. In addition, Ident-IO (F) is at the lowest position.

\subsection{Al-'IZhaar in LHQ}

Some examples of 'IZhaar were discussed earlier, in the context of the blocking of 'Idghaam. In addition, a selection of other instances is presented in the following sections. Al-'IZhaar literally means to be overt. In the science of tajweed, it is defined as: "to pronounce the letters from their makhraj, clearly and distinctly, without any changes" (Read with tajweed rules, n.d.). Thus, it is a phenomenon in which the sound is produced obviously without any change. It is pronounced from its place of articulation clearly and in an obvious way (Czerepinshki \& Swayd, 2000, p.41). The reason behind 'IZhaar is due to the complete different phonetic properties of the two sounds. The phonological process of Al'IZhaar occurs in the Holy Qur'an in three cases:

(a) $/ \mathrm{n} / \mathrm{saakinah}$ followed by one of the pharyngeal sounds $/ /, \mathrm{h}, \mathrm{f}, \mathrm{S}, \mathrm{\gamma}, \mathrm{x} /$,

(b) $/ \mathrm{m} /$ saakinah followed by any mutafarrik other than $/ \mathrm{m} /$ and $/ \mathrm{b} /$, and

(c) $/ 1 /$ sound of the definite article followed by one of the lunar sounds (/'/, /b/, /y/, /f/, /3/, /k/, /w/, /y/, /x/, /f/, / / /, /q/, /m/, h/) (Abdel-Hameed, 2009, pp.171, 172, 190, 196).

\subsubsection{Analysis}

\subsection{1.'IZhaar of $/ \mathrm{n} /$ followed by one of the pharyngeal sounds $/$, $, h, h$, $\underline{\mathbf{f}, \mathrm{X}, \mathrm{x} /}$}

One condition in which 'IZhaar occurs is when $/ \mathrm{n} /$ saakinah either of a consonant or a nunation is followed by one of the six "throat sounds" or "pharyngeal sounds" or "falqi sounds", called as such because they are

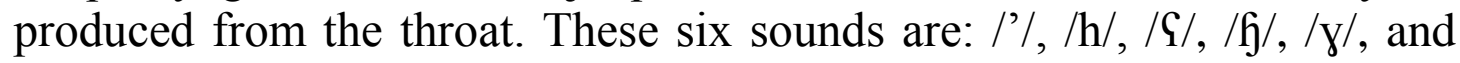
$/ \mathrm{x} /$. In this case, $/ \mathrm{n} /$ is pronounced clearly (Read with tajweed rules, n.d.). Sibawayh (n.d.) indicates that when $/ \mathrm{n} /$ combines with one of the six pharyngeal consonants mentioned above, it does not change its phonetic value; it is pronounced clearly. He asserts that no assimilation or hiding takes place in this case. He clarifies that the reason behind 'IZhaar is that 
the places of articulation of the six pharyngeal sounds are far apart from that of $/ \mathrm{n} /$ and they "do not have the strength to change the Nuun" (as cited in An-Nasser, 1985, p.119). Al-Jazariy (798 Ah) sums up 'IZhaar of $/ \mathrm{n} /$ followed by one of the pharyngeal sounds /', h, f,, , $\mathrm{\gamma}, \mathrm{x} /$ in the following line:

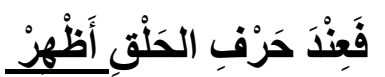

Jazariyyah 66)

Consequently, under this condition, 'IZhaar is better than 'Idghaam and 'Ikhfaa'.

\subsubsection{1.' IZhaar of /n/ followed by /'/ between two words}

Example (15) illustrates 'IZhaar of /n/ followed by /'/ between two successive words:

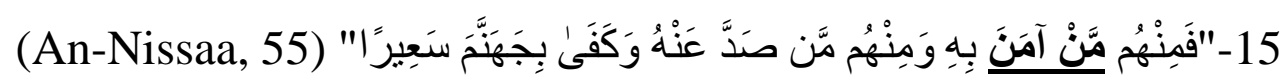
15- "Then some of them believed in it, and some turned away from it; yet sufficient is Hell, the flaming Fire!" (Al-Awfa tran.).

Example (15) exhibits that when $/ \mathrm{n} / \mathrm{in} / \mathrm{man} /$ is followed by $/ ' /$ in /'aa/, no change occurs. The $/ \mathrm{n} /$ sound is fully pronounced. This is due to the complete difference of the phonetic features between $/ \mathrm{n} /$ and $/ \%$. Thus, the input form /man.'aa.ma.na/ remains as it is in the output [man.'aa.ma.na] (Abdel-Hameed, 2009; An-Nabulsi, 2008).

\section{Table (15)}

\begin{tabular}{|r|c|c|}
\hline Input: & $\begin{array}{c}\text { Ident-IO } \\
(\mathbf{F})\end{array}$ & $\begin{array}{c}\text { Share f } \\
(\mathbf{M})\end{array}$ \\
\hline b.[ma.'aa.ma.na/ & & $*$ \\
\hline a.[man.'’aa.ma.na] & $* !$ & \\
\hline c.[maN '.'aa.ma.na] & $* !$ & \\
\hline
\end{tabular}

Table (15) shows that candidate (a) [man.'aa.ma.na] is the optimal output form and the real pronounced one, in which $/ \mathrm{n} /$ is pronounced clearly before /'aa/ mutafarrikah. This is due to the complete difference in features between $/ \mathrm{n} /$ and $/ \%$. The result is the occurance of the sequence 
[n']. Candidate (a) obeys Ident-IO (F), in which the sounds of the input form /man.'aa.ma.na/ are identical to those of the output form [man.'aa.ma.na]. As a result, it violates Share $\mathrm{f}(\mathrm{M})$ in which $/ \mathrm{n} / \mathrm{shares}$ no feature with $/$ '/ sound. Both candidates (b) [ma' 'aa.ma.na] ('Idghaam) and (c) [maN '.'aa.ma.na] ('Ikhfaa') are prohibited. Accordingly, it is noticed that the ranking of the previous constraints, upon which 'IZhaar is applied, is: Ident-IO (F) outranks Share $\mathrm{f}(\mathrm{M})$, in other words, Ident-IO $(\mathrm{F})>$ Share $\mathrm{f}(\mathrm{M})$. The above ranking of constraints in which Ident-IO (F) outranks Share $\mathrm{f}(\mathrm{M})$ is also applied to the following examples: [man.ha.3a.ra] (Al-Hashr, 9), [min.Sin.di] (Al-Baqarah, 79), and [min.xa.yi.rin] (Al-Baqarah, 110).

\subsection{2.'IZhaar of /m/ saakinah followed by any mutafiarrik other than}

\section{/m/ and /b/ between two words}

Another case in which 'IZhaar happens is that in which $/ \mathrm{m} /$ saakinah is followed by any Arabic sound other than $/ \mathrm{m} /$, which leads to 'Idghaam; or $/ \mathrm{b} /$, which prompts 'Ikhfaa'. Thus, the $/ \mathrm{m} /$ sound is pronounced clearly and obviously (Abdel- Hameed, 2009; An-Nabulsi, 2008; Czerepinshki and Swayd, 2000). Al-Jazariy (798 Ah) indicates that readers must take care not to apply 'Ikhfaa' when $/ \mathrm{m} /$ is followed by $/ \mathrm{w} /$ or $/ \mathrm{f} /$ :

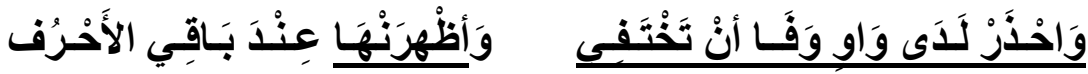

Jazariyyah 64)

The following example manifests how 'IZhaar of $/ \mathrm{m} /$ saakinah followed by /f/ mutafarrikah works in two words:

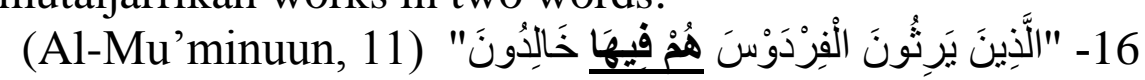
16-"Who will inherit Paradise, and live in it forever" (Al-Awfa tran.)

Example (16) reveals that when $/ \mathrm{m} /$ saakinah is followed by $/ \mathrm{f} /$ mutafarrik, $/ \mathrm{m} /$ is pronounced clearly. Thus, /hum fii.haa/ remains [hum.fii.haa] فِ فِيها and nothing changes (Abdel-Hameed, 2009; AnNabulsi, 2008; Swayd, n.d.). In spite of the closeness of the features between $/ \mathrm{m} /$ and $/ \mathrm{f} /$, since $/ \mathrm{m} /$ is bilabial and $/ \mathrm{f} /$ is labio-dental, yet, $/ \mathrm{m} /$ is not assimilated to $/ \mathrm{f} /$ and 'IZhaar is triggered instead. The reason is that $/ \mathrm{m} /$ is stronger than $/ \mathrm{f} /$, due to its nasality: $/ \mathrm{m} /$ is [+nasal] while $/ \mathrm{f} /$ is [nasal] (Abdel-Hameed, 2009, pp.191-192).

Table (16)

Input: Ident-IO $\quad$ OCP-




\begin{tabular}{|r|c|c|}
\hline /hum.fii.haa/ & (F) & [+labial] \\
\hline \multirow{\xi}{*}{ a.[hum.fii.haa] } & & $*$ \\
\hline b.[huf fii.haa] & $* !$ & \\
\hline c.[huM .fii.haa] & $* !$ & $*$ \\
\hline
\end{tabular}

Table (16) presents [hum.fii.haa]_هُ هُ فِيَها as the optimal output candidate. It obeys Ident-IO (F), because the output form is identical to the input form. Moreover, OCP-[+labial] is violated as both $/ \mathrm{m} /$ and $/ \mathrm{f} /$ have close features, both are [+labial] sounds, yet, assimilation does not take place and they are pronounced clearly due to the strong nasality feature of $/ \mathrm{m} /$, which prevents assimilation to take place. Candidate (b) [huf fiihaa] in which $/ \mathrm{m} /$ assimilates to $/ \mathrm{f} /$ and candidate, (c) [hu $\mathbf{M}^{\sim}$.fii.haa] in which $/ \mathrm{m} /$ is hidden into /f/ are prohibited. As a result, it is noted that Ident-IO (F) dominates and is ranked over OCP-[+labial]. In other words, the ranking of these constraints is: Ident-IO $(\mathrm{F})>\mathrm{OCP}-$ [+labial]. Thus, 'IZhaar is better than 'Ikhfaa' in which 'IZhaar asserts the violations of OCP-[+labial] and obeys Ident-IO (F). Additional examples that follow the same ranking of constraints are: [wa.hum.fa.ri.乌uun] (At-Tawbah, 50) and [乌i.saa.bu.hum.wa.hum fii yaf.la.tin] (Al-'anbiyaa', 1).

\subsection{3. 'IZhaar of /l/ of the definite article /'al/ followed by lunar sounds within one word}

There is an extra condition, in which 'IZhaar occurs, concerning /1/ of the definite article /'al-/. As noted ealier, there are two possibilities for /1/ of the definite particle: either 'IZhaar or 'Idghaam. /1/ of the definite article is pronounced clearly when added to a noun starting with one of the following lunar sounds: //, /y/, /b/, / $/, / \mathrm{h} /, / 3 /, / \mathrm{k} /, / \mathrm{w} /, / \mathrm{x} /, / \mathrm{f} /, / \mathrm{S} /$, $/ \mathrm{q} /, / \mathrm{m} /, \mathrm{h} /$. The reason is that $/ \mathrm{l} /$ and these lunar sounds differ in their phonetic features (Abdel-Hameed, 2009; Czerepinshki \& Swayd, 2000). Al-Jamzuuriy (1198 Ah) sums up these rules in the following lines:
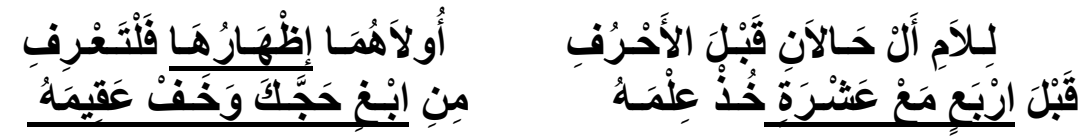
'ATfaal 24-25)

(Tuffatu-1-

Consequentely, when /1/ of the definite article comes before one of the lunar sounds, 'IZhaar is preferred to 'Idghaam.

\subsubsection{1. 'IZhaar of /l/ of the definite article /'al/ followed by $/ \mathrm{m} /$ within one word}

The following example models 'IZhaar of $/ 1 /$ of the definite article /'al/ followed by $/ \mathrm{m} /$ :

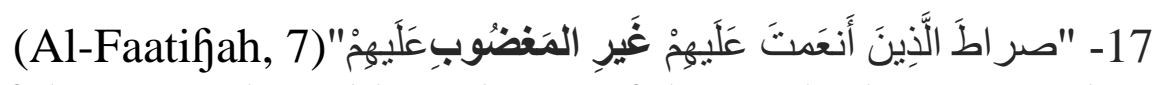

17-"The path of those You have blessed, Not of those who have earned Your anger, nor those who have gone astray."(Al-Awfa tran.)

Example (17) presents the input /'al.may.duub/المغضوب, which does not change in its output form ['al .may.duub] المغضوب. Thus, when /1/ of the definite article is followed by $/ \mathrm{m} /, / 1 /$ is pronounced clearly and 'IZhaar is triggered. The reason behind this is that $/ 1 /$ and $/ \mathrm{m} /$ differ in their phonetic features: / $/$ / is a lateral alvealor sound but $/ \mathrm{m} /$ is a nasal bilabial sound (Amer, 2011).

Table (17)

\begin{tabular}{|r|c|c|c|}
\hline Input: & $\begin{array}{c}\text { Ident-IO } \\
\text { (F) }\end{array}$ & $\begin{array}{c}\text { *Son.Gem } \\
(\mathbf{M})\end{array}$ & $\begin{array}{c}\text { Share f } \\
(\mathbf{M})\end{array}$ \\
\hline a.duub/ & & & $*$ \\
\hline $\begin{array}{r}\text { b.['al.may.duub] } \\
\text { a.duub] }\end{array}$ & $* !$ & $* !$ & \\
\hline
\end{tabular}

Table (17) indicates that the optimal output candidate (a) ['al.may.quub] obeys Ident-IO $(\mathrm{F})$ in which the sounds in the input form /'al.may.duub/ are identical to the sounds in the output form ['al.may.quub]. In addition, it obeys *Son.Gem (M) as it prevents sonorant gemintion. Yet, it violates Share $\mathrm{f}(\mathrm{M})$ because /l/ shares no feature with the following $/ \mathrm{m} /$. As a result, it is observed that Ident-IO (F) outranks *Son.Gem $(\mathrm{M})$, while *Son.Gem (M) dominates Share $\mathrm{f}(\mathrm{M})$, i.e. the ranking of these constraints is: Ident-IO (F)> *Son.Gem (M)> 
Share $\mathrm{f}(\mathrm{M})$. This ranking of constraints is also applied to other examples as: ['al-musawwir] (Al-Hashr, 24) and ['al-mulk] (Al-Baqarah, 251).

\subsubsection{List of constraints in Al-'IZhaar in the selected cases}

To sum up, the previous analyses prove that Al-'IZhaar in the chosen sets from LHQ is built upon the following ranking of constraints:

(a) Ident-IO (F) > Share $\mathrm{f}(\mathrm{M})$;

(b) Ident-IO (F) > OCP-[+labial];

(c) Ident-IO (F) $>*$ Son.Gem $>$ Share $\mathrm{f}(\mathrm{M})$.

Hence, in 'IZhaar, Ident-IO (F) is at the highest rank.

\section{Conclusion}

This study attempted to examine three of the tajweed rules: Al'Idghaam ('Idghaam Al-Mutamaathilayn- 'Idghaam Al-Mutajaanisayn'Idghaam Al-Mutaqaarbayn), Al-'IZhaar, and Al-'Ikhfaa' under the theoretical framework of optimality theory in phonology. These tajweed rules are bounded by certain constraints which the study sought to reveal. Furthermore, it endeavored to create a hierarchy of the Classical Arabic constraints upon which these three rules are built. The study started by examining Al-'Idghaam: 'Idghaam Al-Mutamaathilayn, 'Idghaam AlMutajaanisayn, and 'Idghaam Al-Mutaqaarbayn in the chosen examples.

It was revealed that 'Idghaam Al-Mutamaathilayn under OT is based on the following ranking: OCP-total> Share $\mathrm{f}(\mathrm{M})$, Onset-position (M) > *Son.Gem (M), Max-IO (F) > Ident-IO (F). Thus, OCP-total is at the highest rank and outranks other constraints. It dominates Share $\mathrm{f}(\mathrm{M})$ and Onset-position (M). Share f (M) and Onset-position (M) are ranked over *Son.Gem (M) and Max-IO (F). Finally, Ident-IO (F) is in the lowest rank. The study also illustrates that 'Idghaam Al-Mutamaathilayn is blocked in the selected example under the following rankings: (a) Ident-IO (F) >*Son.Gem (M) > OCP-[+labial], *VV.Semi-vowel (M) > Share $\mathrm{f}(\mathrm{M})$. Consequentely, Ident-IO $(\mathrm{F})$ is at the highest rank in the blocking of 'Idghaam Al-Mutamaathilayn ('IZhaar) and Share $\mathrm{f}(\mathrm{M})$ is at the lowest rank. 
It was also observed that in 'Idghaam Al-Mutajaanisayn OCP[+coronal] is positioned in the highest rank followed by Share $\mathrm{f}(\mathrm{M})$ and Onset-position (M), then Max-IO (Emphatic) (F). Ident-IO (F) is in the lowest rank. Moreover, the study proved that 'Idghaam AlMutaqaaribayn of the chosen examples is based on the following rankings:

(1) OCP-[+nasal], OCP-[+sonorant] > Share f (M), Onset-position (M) > *Son-Gem $(\mathrm{M})>$ Ident-IO $(\mathrm{F})$;

(2) OCP-[+coronal], OCP-[+sonorant], and OCP-[+lateral], *lateral.trill> Share f (M), Onset-position (M)> *Son.Gem (M) > Ident-IO (F);

(3) OCP-[+sonorant] > Share f (M), Onset-position (M)> Max-IO (Nasal) $(\mathrm{F})>*$ Son.Gem $(\mathrm{M})>\operatorname{Ident}-\mathrm{IO}(\mathrm{F})$;

(4) OCP-[+coronal], OCP-[+sonorant], *Nas (N).Lateral (M) > Share f $(\mathrm{M})$, Onset-position (M) > *Son-Gem (M), Max-IO (Nasal) (F)> Ident-IO (F);

(5) OCP-[+dorsal], ${ }^{*}[\mathrm{qk}](\mathrm{M})>$ Share f (M), Onset-position (M) > IdentIO $(\mathrm{F})$, and

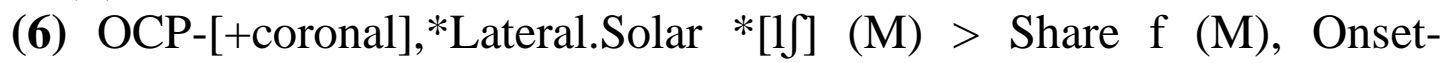
position $(\mathrm{M})>\operatorname{Ident}-\mathrm{IO}(\mathrm{F})$.

Moreover, the study investigated Al-'Ikhfaa' in LHQ. It found that 'Ikhfaa' in the examined instances is built upon the following rankings: (1) OCP-[+coronal] $>$ Max-IO (Nasal) (F)> Ident-IO (F), and (2) OCP[+labial] $>$ Max-IO (Nasal) $(\mathrm{F})>$ Ident-IO $(\mathrm{F})$. It is deduced that OCPplace: OCP-[+coronal] and OCP-[+labial] occupies the highest rank. Then Max-IO (Nasal) (F) outranks Ident-IO (F). As for Al-'IZhaar, the study proved that Al-'IZhaar, according to the cases selected in the study, is based on the following rankings:

(1) Ident-IO (F) > Share f (M);

(2) Ident-IO (F) $>$ OCP-[+labial], and

(3) Ident-IO (F) $>*$ Son.Gem $>$ Share $\mathrm{f}(\mathrm{M})$.

The ranking reflects that in 'IZhaar, Ident-IO $(\mathrm{F})$ is at the highest rank. 


\section{5- The ranking of constraints discussed in the present study}

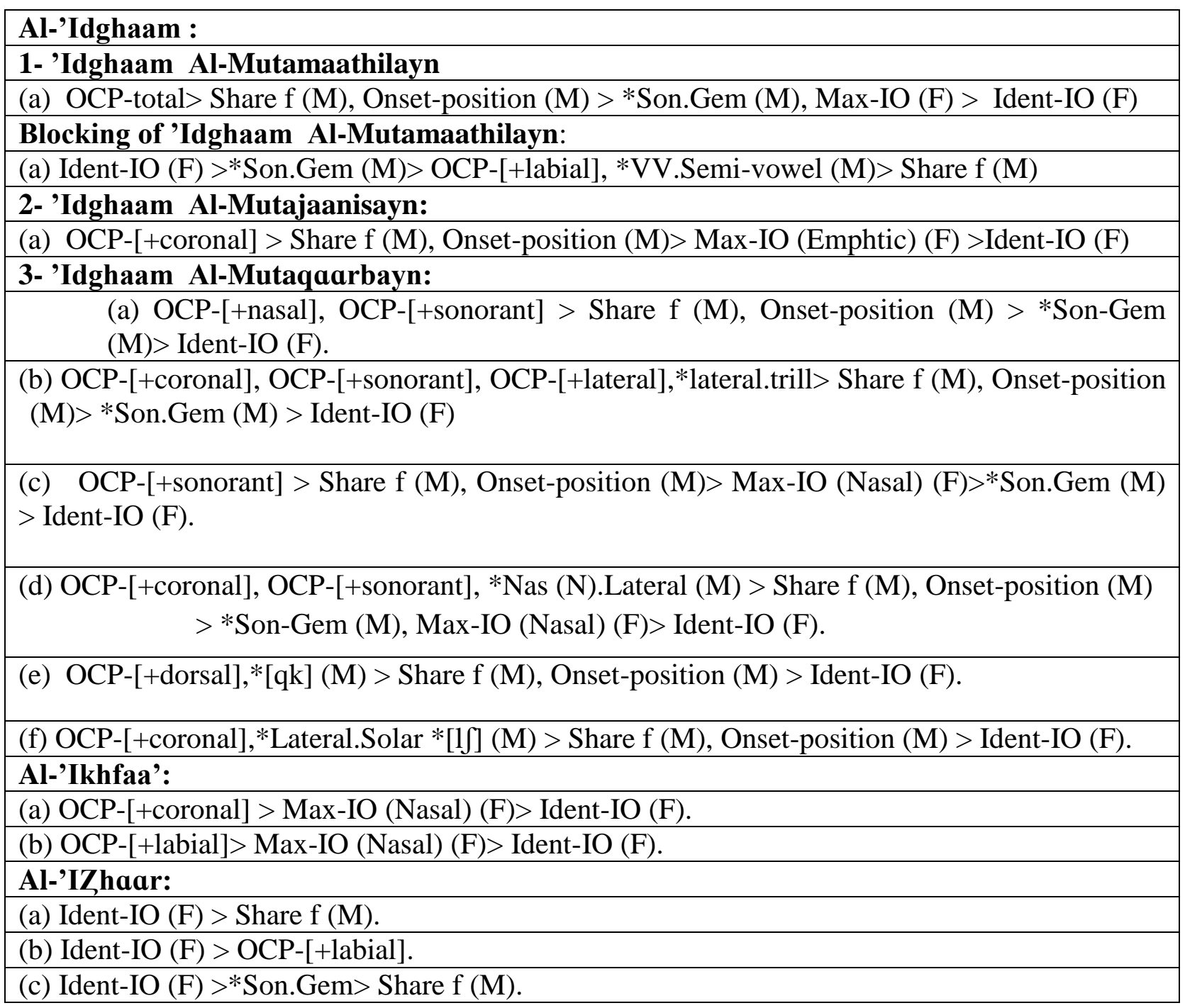

